\title{
ESTUDIO DE IMPACTO AMBIENTAL DE UN AERÓDROMO
}

\author{
(STUDY OF THE ENVIRONMENTAL IMPACT OF AN AERODROME)
}

Domingo Gómez Orea, Dr. Ing. Agrónomo; Agustín González, Morera, Ing. Agrónomo; David Pereira Jerez, Ing. Agrónomo; y Teresa Villarino Valdivielso, Dr. Ing. de Montes

Fecha de recepción: 13-X-95

ESPAÑA

\section{RESUMEN}

Los aeropuertos y aeródromos son infraestructuras de transporte que, además de contribuir a la movilidad de las personas y mercancias, fomentan el desarrollo porque promocionan nuevas actividades, estimulan las iniciativas locales y revalorizan los territorios contiguos.

Se expone en este articulo una sintesis del Estudio de Impacto Ambiental de un futuro aeródromo, actualmente en fase de proyecto, cuya vinculación al procedimiento administrativo de ELA, viene determinada por la legislación especifica vigente en la actualidad: R.D. 1302/86. El documento técnico sobre el que se hace el estudio corresponde al plan especial del aeródromo.

Lin criterio básico en la concepción de aeropuertos y aeródromos privados es la compatibilidad con la habitabilidad del entorno y con las condiciones ecológicas y paisajísticas, criterio que debe intervenir en la orientación de las pistas, trayectorias en la maniobras de despegue y aterrizaje... incluso en la localización y diseño de estacionamientos, hangares y demás instalaciones. Esta idea aconseja concebir el proyecto con sensibilidad ambiental, desde las primeras fases, evitando repercutir la responsabilidad en este tema al estudio de impacto ambiental.

Se adopta un estilo propio de la divulgación, en la idea de que más que los datos técnicos, que sólo interesan a la tramitación del proyecto, el lector encontrará mayor utilidad en los aspectos metodológicos y en aquéllos que han permitido al equipo redactor formar criterio sobre los costes y beneficios ambientales del proyecto y sobre la aceptabilidad de éste, en suma.

Se ha utilizado una metodología clásica, de acuerdo con los requerimientos del reglamento de EIA, cuyas tareas concatenadas aparecen en el diagrama de flujos de la Figura 1 .

\section{SUMMARY}

Airports and aerodromes are transport infratructures which, apart from contributing to the mobility of people and goods, favour social development, since they promote new activities, stimulate local initiatives and reassess bordering areas.

This article presents a synthesis of the Environmental Impact Study of a future aerodrome, whose design project is way at present. The aerodrome is submitted to the EIA administrative procedure due to the currently applicable specific legislation. R.D. 1302/86. The technical document submitted for study is the special plan of the aerodrome.

One of the basic criteria in the conception of airports and private air fields is the compatibility with the habitability of the environment as well as with the ecological and landscape conditions. This criteria should play a part in the orientation of the runways, trajectory of the taking off and landing maneuvers..., even in the location and design og the parking spaces, hangars and other facilities. This idea suggests the design be conceived with environmental-friendly sensibility, right from the initial stages, without leaving the responsibility of this issue to the environmental study impact.

The present study has its own style of approaching the dissemination, consisting of the idea that the reader will find the methodological aspects more useful than the technical data which are of consequence only in the handling-of the different project stages. The aspects which are also considered important for the reader are those which allowed the team of editors to form their criteria on the issues of expenses, environmental benefits of the design, its acceptability, etc.

The methodology applied is a classical one, in accordance with the requirements of the EIA regulations. The tasks of the method used are given in the flow chart in Fig. 1. 


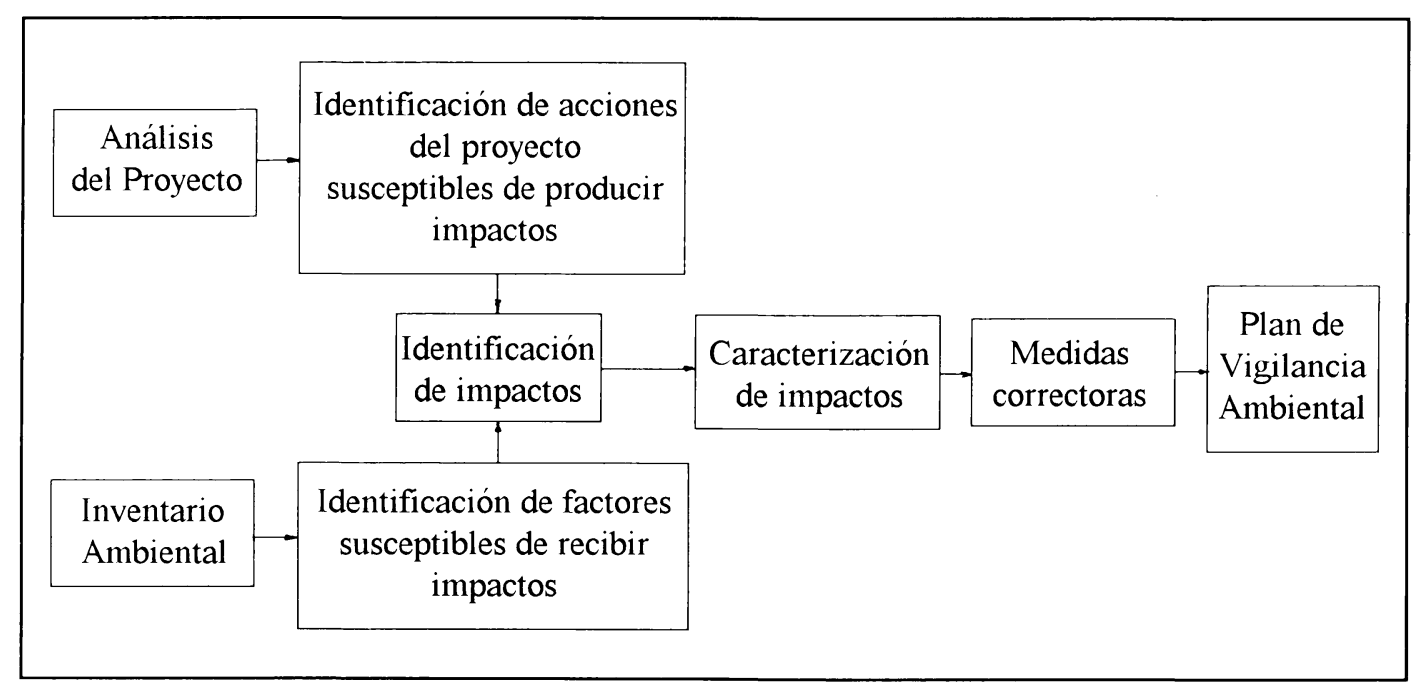

Fig. 1.- Metodología.

\section{IDENTIFICACIÓN DE IMPACTOS}

La identificación de impactos se basa en el conocimiento del proyecto a evaluar y sus alternativas y en el estudio del medio en el que se ubica, para analizar después la relación entre ambos.

\subsection{El proyecto y sus alternativas}

La actividad cuyo impacto se desea evaluar consiste en la construcción y explotación de un aeródromo, dotado de pista de despegue/aterrizaje y diversas dependencias que más adelante se describen.

Pretende sustituir a uno existente en la misma zona, que ha quedado pequeño y desfasado respecto a los requerimientos actuales de la navegación aérea. Se ha contemplado la posibilidad de adaptar éste a las nuevas necesidades, pero los inconvenientes superan tanto a las ventajas que se ha optado por una nueva actuación.

Su localización corresponde a una superficie de páramo (Figura 2), a $920 \mathrm{~m}$ de altitud media, sobre un paisaje agrícola en declive (Foto 1), en el que existen dos pequeños núcleos rurales de población y una urbanización de segunda residencia. La selección de tal emplazamiento ha incorporado criterios de carácter ambiental a los más comúnmente considerados en este tipo de proyectos; en conjunto los factores de localización adaptados han sido los siguientes:

-Condiciones atmosféricas.

-Calidad y fragilidad ambiental del territorio.

-Tipo de desarrollo del área circundante.
-Accesibilidad al transporte terrestre.

-Disponibilidad de terreno para posible ampliación.

-Presencia de otros aeródromos en la zona.

-Economía en la construcción.

-Proximidad de demanda aeronáutica.

Objetivos del proyecto

El aeródromo pretende acoger distintas actividades que demanda actualmente la aviación civil, general, docente y deportiva; sus objetivos principales son los siguientes:

- Acoger el tráfico aéreo correspondiente a la docencia de profesiones aeronáuticas, generado por la creación de una "escuela de pilotos e instructores" anexa y vinculada al propio aeródromo

-Reparación, mantenimiento y custodia de aparatos de aviación general. Al mismo tiempo, docencia para mecánicos de motores de aviación y otras profesiones aeronáuticas.

-Colaborar en la prestación de servicios de Protección Civil.

-Promover la cultura aérea (fotografia aérea) y la educación deportiva.

Además, de forma secundaria, se pretende también que sirva como:

-Base operativa para la prevención y lucha contra incendios forestales. 


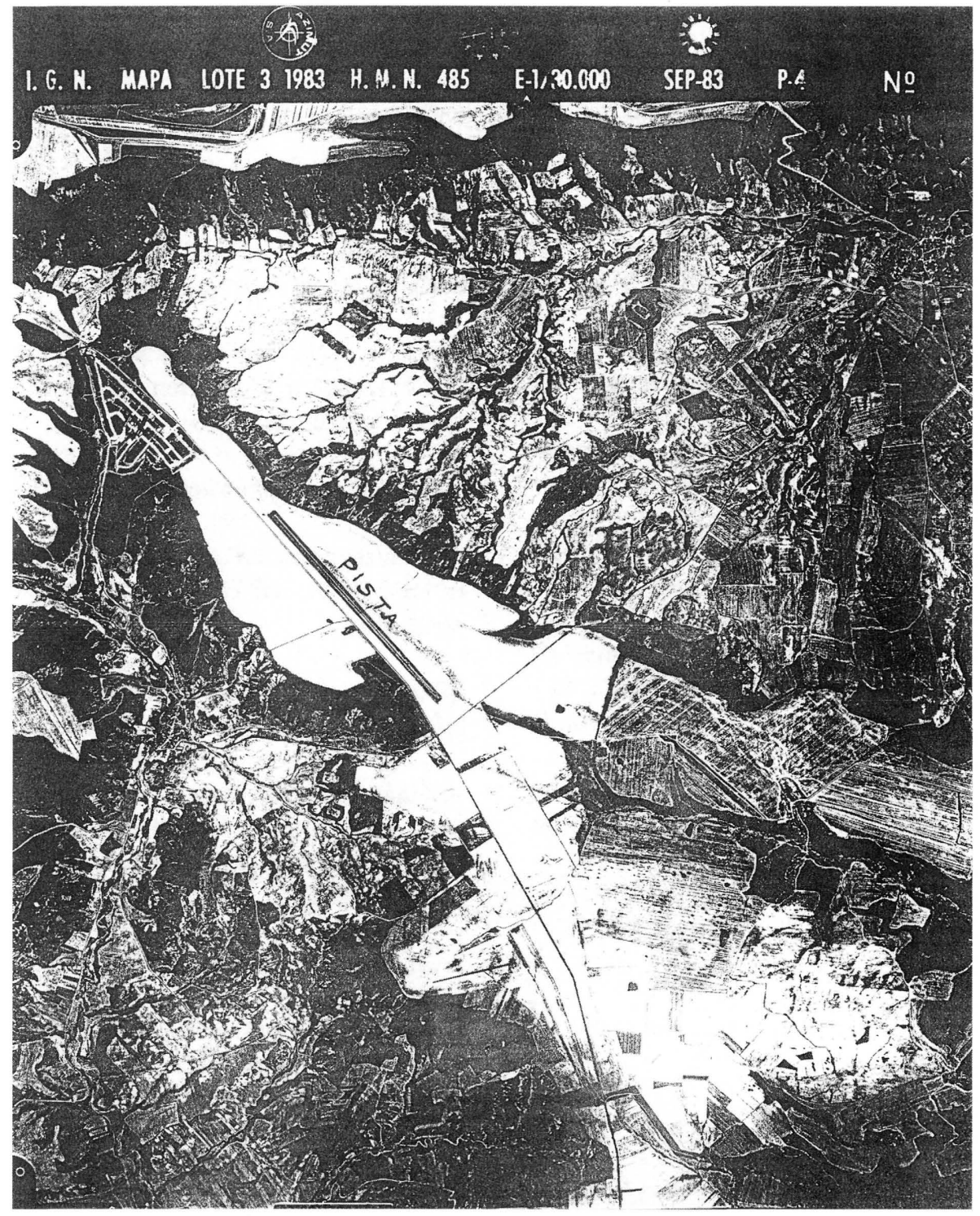

Fig. 2.- Fotografia aérea de la zona.

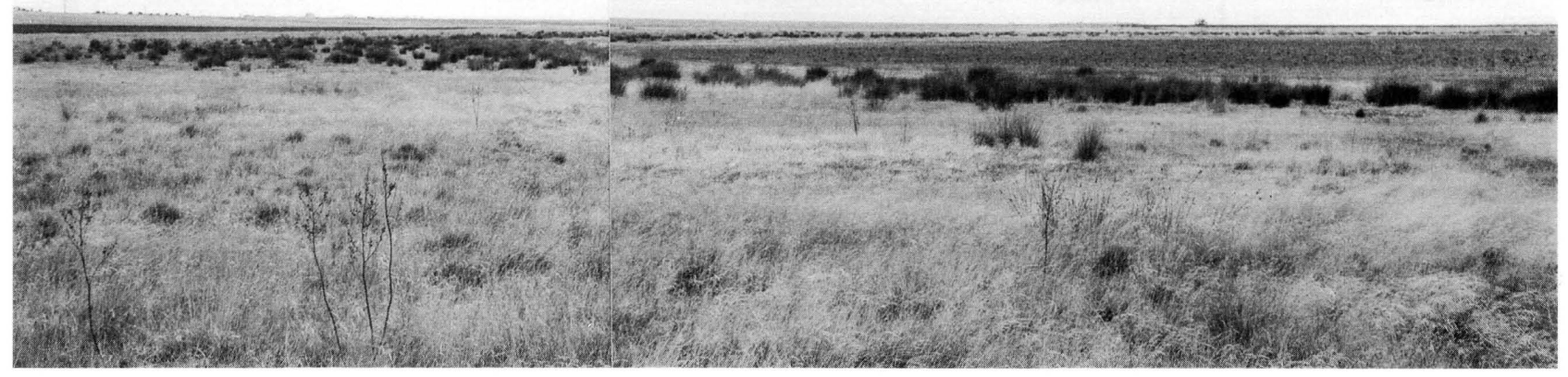

Foto.1.- Macrounidad de paisaje intrinseco. Superficie de páramo en el entorno directo de la actuación. Amplitud del horizonte de vistas en ausencia de obstáculos, irrelevancia de formas. En este escenario la actuación se absorbe fácilmente con la precaución de no construiren altura, sino de forma pegada al terreno. 
-Base para ambulancias aéreas (transportes de órganos para transplantes humanos, por ejemplo).

-Vigilancia de redes eléctricas y de policía aérea.

-Aeropuerto de emergencia para situaciones comprometidas.

Fases, elementos e instalaciones previstas

El proyecto se ejecutará en dos fases. En la primerá, se acometerá la ejecución de los siguientes elementos:

-Pista principal, de aterrizaje y despegue con una longitud mínima de $1.500 \mathrm{~m}$, prolongados en otros $500 \mathrm{~m}$ sobre pista de tierra, una anchura de $23 \mathrm{~m}$ y una zona de protección a ambos lados de $33,5 \mathrm{~m}$, lo que le confiere el carácter de aeródromo industrial.

-Pista de Rodaje y áreas de espera, con una longitud de $1.500 \mathrm{~m}$, anchura $18 \mathrm{~m}, \mathrm{y}$ zonas de protección de $45 \mathrm{y}$ $25 \mathrm{~m}$ a ambos lados respectivamente, para maniobra de aviones.

-Áreas de Plataforma, Torre de Control y Escuela de Pilotos, con una superficie total de $52.232 \mathrm{~m}^{2}$.

-Área de hangares, talleres y campos con una superficie total de $499.376 \mathrm{~m}^{2}$.

- Área de Residencia y Escuela para la docencia de profesiones aeronáuticas: $26.818 \mathrm{~m}^{2}$.

-Zonas Verdes: $25.000 \mathrm{~m}^{2}$.

- Aparcamiento de coches con capacidad suficiente para albergar los vehículos del público y del personal del aeródromo.
-Helipuerto con capacidad para cuatro helicópteros.

-Servicios de seguridad espacial, mantenimientoy asistencia a pilotos.

-Dos depósitos subterráneos parael repostado de carburante, con 25.000 litros de capacidad cada uno, dotados con las correspondientes bombas, así como un camión de 5 toneladas para reponer carburante a los aviones.

-Depósito y unidad móvil para el suministro, a aquellos aviones que lo precisen, de oxígeno en fase gaseosa y envasado a alta presión.

\section{-Observatorio meteorológico}

En una segunda fase se incrementaráel recorrido de la pista en $500 \mathrm{~m}$, así como las zonas y servicios correspondientes.

En total, todo ello podría culminar en un aeródromo con una pista de 3.000 metros aproximadamente.

Además se establecerá un Plan de Emergencia contra incendios y otras eventualidades que el mayor tráfico previsto requiere, para cubrir los posibles accidentes que puedan suceder.

\section{Tráfico y operaciones previstas}

El número de operaciones (despegues, tomas de tierra y estacionamiento) previstas, en la fase de explotación será determinante de uno de los impactos más específicamente asociados a este tipo de proyectos: el ruido; como base para el cálculo del impacto sonoro, se adopta, en este caso, el tráfico previsto a un horizonte de 6 años desde el comiezo de la explotación, momento en el que se considera relativamente estable el número de operaciones (Tabla 1).

TABLA 1

Operaciones previstas

\begin{tabular}{||c|c|c||}
\hline \multirow{2}{*}{ AÑO } & \multicolumn{2}{|c|}{ ACTIVIDADES } \\
\cline { 2 - 3 } & TOMA DE TIERRA & ESTACIONAMIENTO \\
\hline 1 & 900 & 400 \\
\hline 2 & 990 & 440 \\
\hline 3 & 1.089 & 484 \\
\hline 4 & 1.198 & 532 \\
\hline 5 & 1.318 & 585 \\
\hline 6 & 1.450 & 644 \\
\hline
\end{tabular}




\subsection{Inventario ambiental}

Se realiza, de acuerdo con el reglamento de EIA, sobre los factores del medio, es decir, los elementos, cualidades y procesos del entorno que determinan la estructura y funcionamiento del entorno presumiblemente alterado y que puede interaccionar con el proyecto.

\section{El clima}

Los parámetros climáticos de intervención directa en la funcionalidad del aeródromo son:la humedad, la temperatura, el viento y la visibilidad.

-La humedad relativa, influye sobre la longitud de la pista, en cuanto que afecta, favorable o desfavorablemente, a la adherencia de los neumáticos al pavimento. La humedad relativa media mensual es máxima en diciembre con un $83,5 \%$ y mínima en julio con un $53,5 \%$.

-La temperatura, interviene en el rendimiento aerodinámico de las aeronaves, por disminuir la densidad del aire y, por tanto, la sustentación.

-Temperatura media anual $13,0^{\circ} \mathrm{C}$

-Temperatura media del mes más cálido .... 23,0 ${ }^{\circ} \mathrm{C}$.

-Temperatura media del mes más frío ........ 4,5 ${ }^{\circ} \mathrm{C}$.

-Temperatura máxima absoluta en el período considerado: $40,0^{\circ} \mathrm{C}$

-Temperatura mínima absoluta en el período considerado: (1-II-1983 y 27-II-1986) $-10,0^{\circ} \mathrm{C}$.

-Oscilación térmica anual (diferencia entre $\mathrm{T}^{\mathrm{a}}$ media del mes más cálido y la $\mathrm{T}^{\mathrm{a}}$ media del mes más frío) $18,5^{\circ} \mathrm{C}$.

-Fecha primera helada 20-X al1-XI

-Fecha última helada $1-\mathrm{V}$

-Duración media del período frío 6 meses.

-El viento incide en la orientación de las pistas. La dirección dominante corresponden al SW, con mucha diferencia sobre las demás (ver rosa de vientos, Figura 3). Las velocidades medias no son en general elevadas, las más altas corresponden a los vientos de dirección NE, pero por ser éstos mucho menos frecuentes que los del SW, el mayor flujo de aire que penetra en la zona corresponde a esta última dirección. La mayor velocidad media mensual, por rumbo, pertenece al $\mathrm{NE}$, con $17 \mathrm{~km} / \mathrm{h}$, en e 1 mes de marzo. La menor velocidad media corresponde al $\mathrm{E}$, con $2 \mathrm{~km} / \mathrm{h}$, también en marzo. El recorrido medio

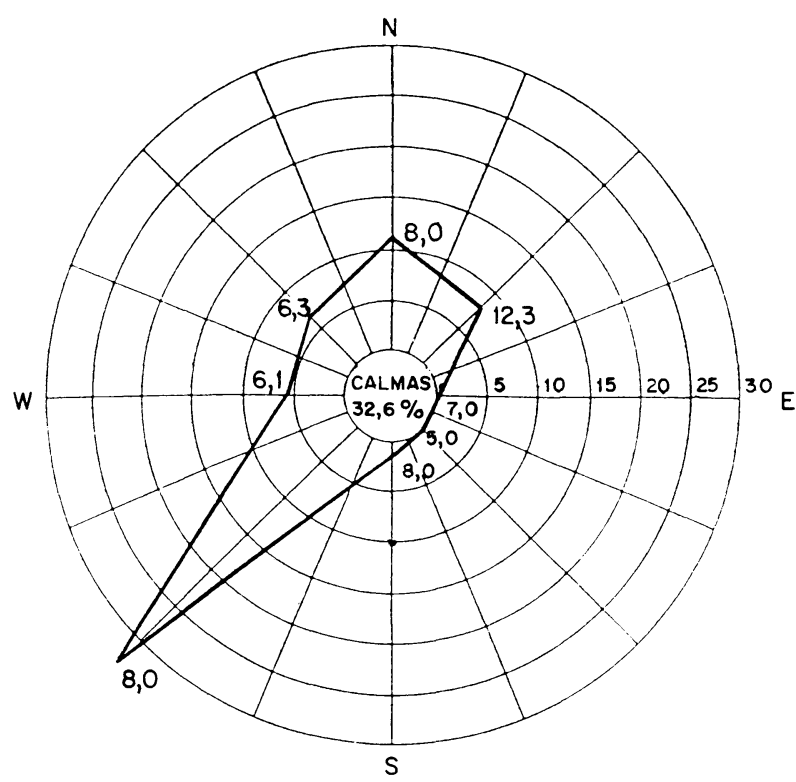

Fig. 3.- Rosa de los Vientos

diario del viento es de $174 \mathrm{~km}$, con un máximo en abril de $210 \mathrm{~km}$ de media por día.

-La visibilidad, afecta a la maniobrabilidad de los aparatos.

\section{Calidad del aire}

Los niveles de contaminación atmosférica pueden considerase inapreciables, debido a la falta de fuentes contaminantes cercanas y a la presencia de vientos regulares durante todo el año que favorecen la alta renovación del aire $y$, por ello, la fácil dispersión de contaminantes. Se puede concluir, por tanto, que la calidad del aire es buena, como corresponde a un área rural deprimida.

En cuanto al ruido, que no es otra cosa que energía disipada, el habitual silencio de la zona queda alterado por la utilización del aeródromo actual, al que sustituirá el que ahora se proyecta.

\section{Geología y geomorfología}

El área de estudio corresponde a una superficie, llana y culminante, de páramo (Foto 2 ), características ventajosas para la instalación del aeródromo porque facilitan las operaciones de vuelo, lo que resulta especialmente interesante para el proyecto en cuanto que uno de sus principales objetivos es la enseñanza a futuros pilotos. Además, la elevada altura de esta plataforma dificulta la formación de nieblas densas, háciendo así posible el uso de las instalaciones durante todo el año.

Este tipo de unidad geomorfológica está muy representada en la zona y fuera de ella, resultando de escaso valor desde el punto de vista ambiental y poco frágil ante la instalación prevista. 


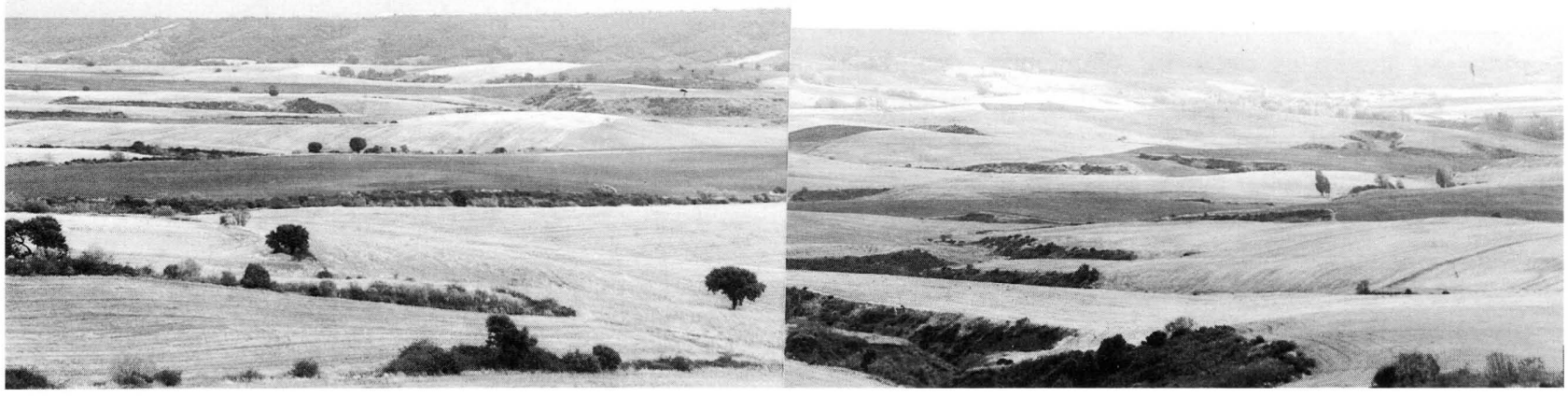

Futo 2.- Aspecto del entorno sobre el que se proyecta el potencial de vistas de la zona en que se ubica la actuación (paisaje extrinseco). Sobre el páramu se percibe con dificultad una actuación existente.
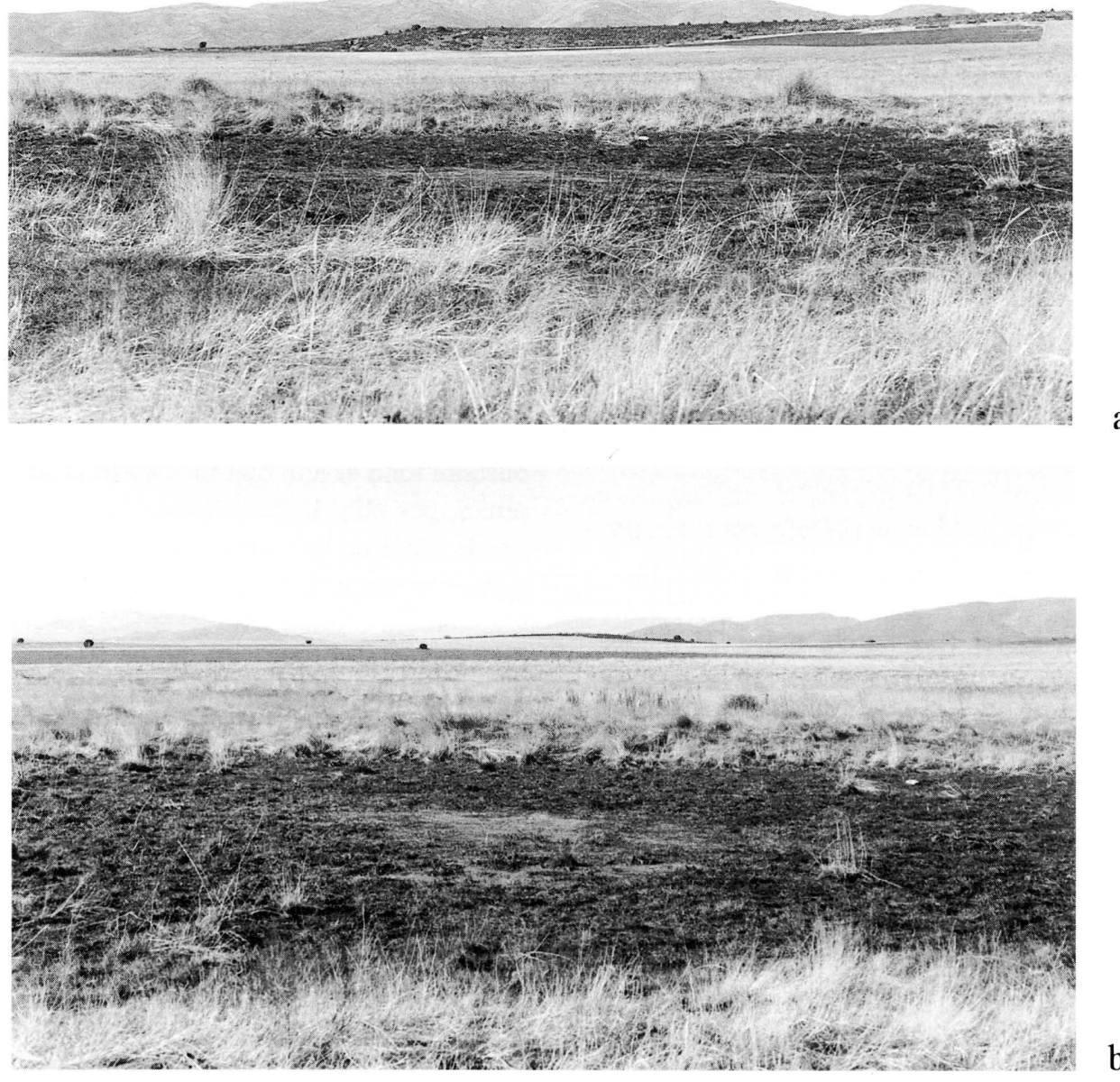

Foto 3.- Las lagunas, Grande (a) y Chica (b), apenas son reconocibles por unas pequeñas charcas que denuncian su presencia y unos herbazales que se desarrollan al amparo de una mayor humedad edáfica.

\section{Hidrogeología e hidrología}

No existen corrientes superficiales de agua en las cercanías del nuevo aeródromo; tan sólo algunos arroyos, secos durante casi la totalidad del año, disecan la superficie del páramo. Tampoco existen acuíferos subterráneos.
Destaca, no obstante, la presencia de dos lagunas (Foto 3), situadas a unos $4 \mathrm{~km}$. al noreste del aeródromo, muy mermadas en el momento de redactar este estudio, cuyo interés no consiste en su posible utilización como recurso hídrico, sino por su condición de humedal con una vegetación y fauna específica, y con funciones importan- 
tes para el refugioy reposo de la fauna migratoria del norte de Europa (Paleártico Occidental).

\section{Suelos}

Según la clasificación “Soil Taxonomy”, los suelos presentes en la zona son ALFISOLES, pobres en humus con un horizonte $\mathrm{Bt}$ (textural) con límite abrupto, lo que indica que son suelos muy viejos. Corresponden a una clase agrológica III, sólo apta para agricultura extensiva, que en la situación de continentalidad climática de la zona, determina la utilización de la técnica del barbecho blanco y unos rendimientos escasos.

\section{Vegetación}

La zona de estudio debió ser un magnífico bosque de quercíneas, roble y encina, que la roturación con fines agrícolas, el carboneo y el pastoreo consuetudinario, han reducido a ciertas manchas refugiadas en las márge- nes escarpadas e incultivables de los arroyos, a algunos linderos y a los escasos ejemplares arbóreos aislados que salpican los cultivos; el abandono progresivo de muchas parcelas de cultivo hace que, sobre ellas, se insinúen tímidamente las fases pioneras del robledal y encinar. En consecuencia nos encontramos con una situación ecológicamente degradada, en estado de regresión muy avanzado, ocasionado por la acción del hombre (Fotos 4 , $5,6,7$ y 8$)$.

En síntesis, existen en la zona tres grandes formaciones vegetales, bien diferenciadas:

-La estepa cerealista, salpicada aquí y allá, de parcelas abandonadas y eriales a pastos en distinto estado de regeneración de la vegetación natural. Destacan los efectos erosivos favorecidos por la quema de rastrojos y por las labores agrícolas, que se unen a los procesos de erosión asociados a las zonas de fuertes pendientes y materiales deleznables que forman las laderas de los barrancos.

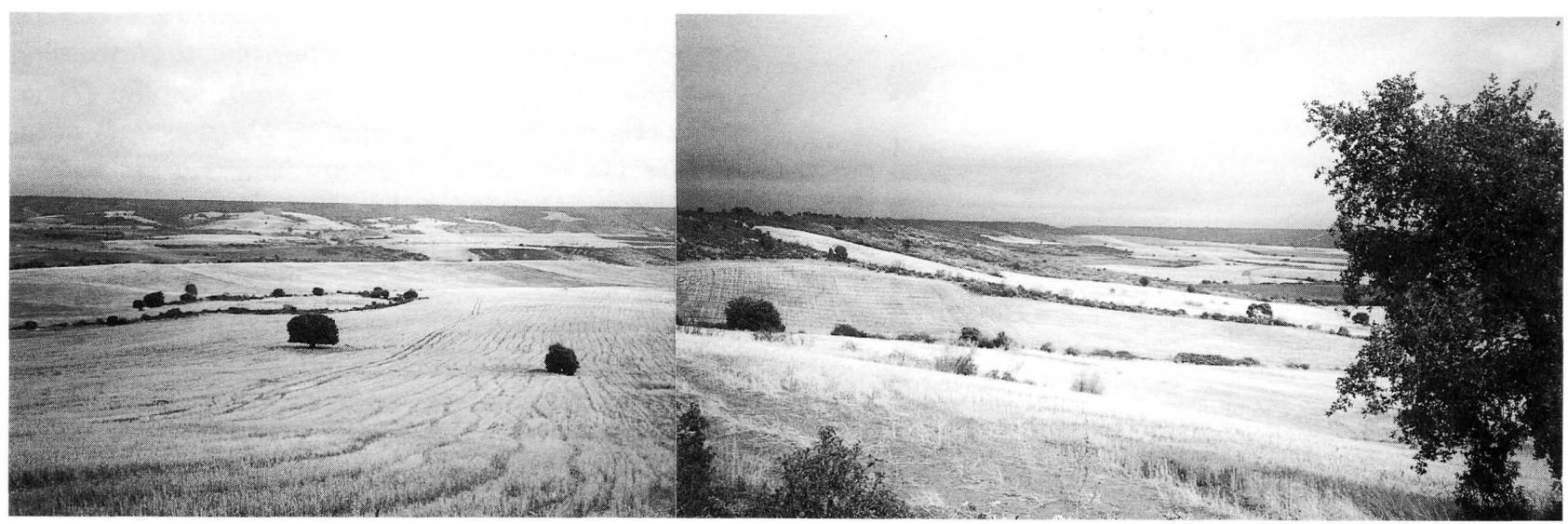

Foto 4.- Panorámica del paisaje en que se inscribe la actuación. Se divisa la línea horizontal que denuncia la superficie del terreno.
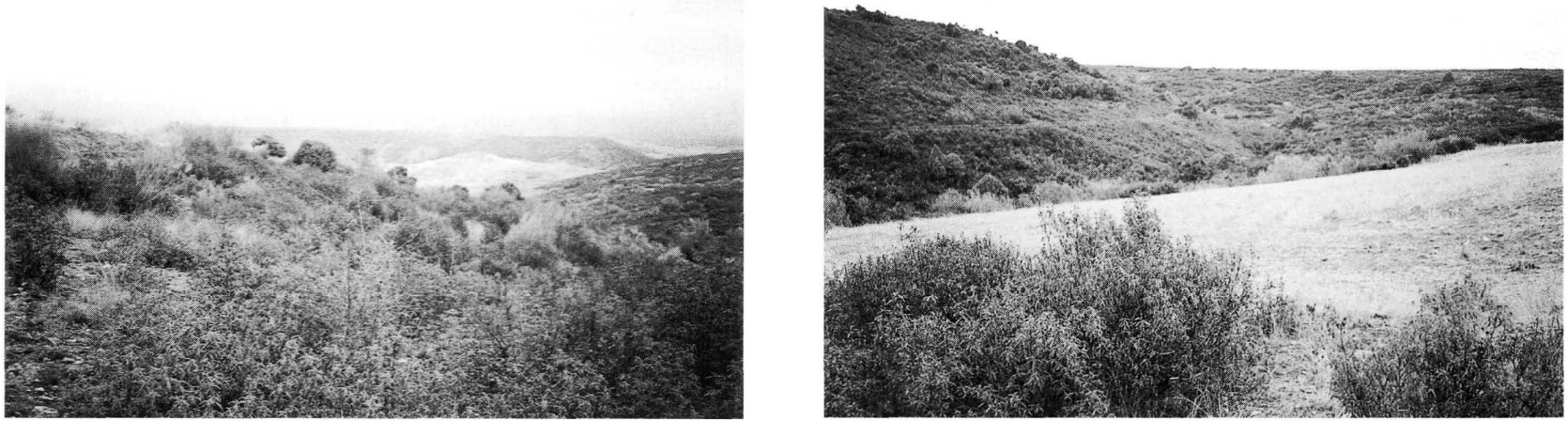

Foto 5.- Aspecto de los arroyos que cortan el páramo mostrando la vegetación residual del primitivo bosque esclerófilo mediterráneo. 

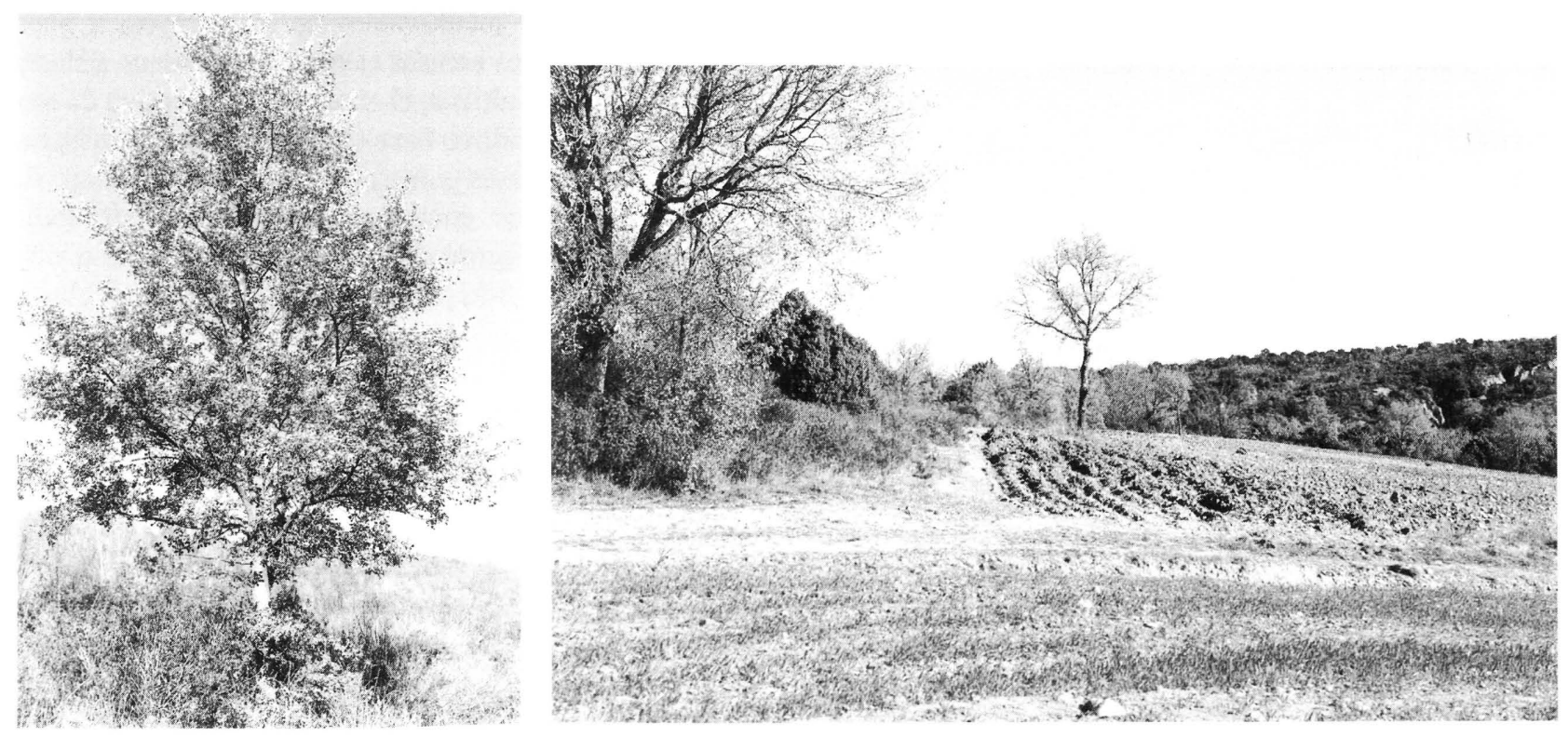

Foto 6.- Ejemplares arbóreos del antiguo bosque.
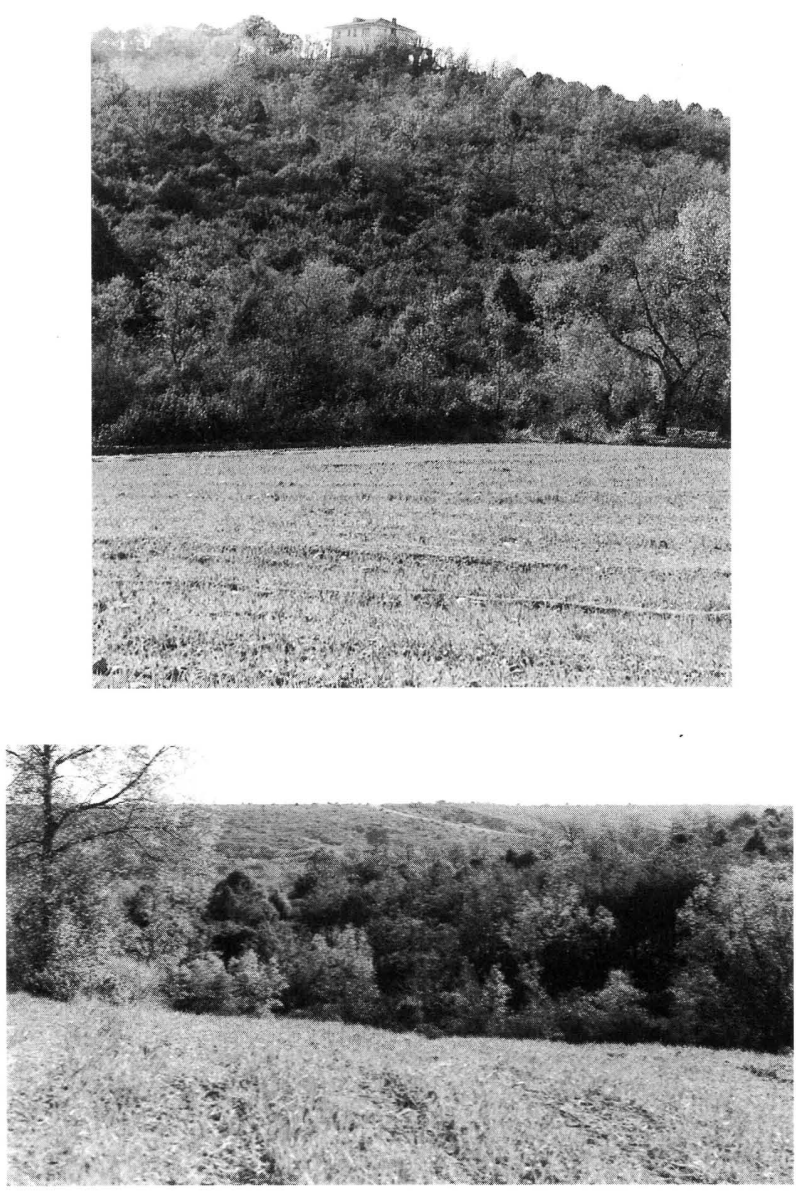

Foto 8.- Mancha mejor conservada del bosque primitivo, que históricamente ha ido cediendo terreno a los cultivos.

(c) Consejo Superior de Investigaciones Científicas Licencia Creative Commons 3.0 España (by-nc)
-Las formaciones de matorral pluriespecífico asociado a ejemplares arbóreos más o menos aislados. El matorral está dominado por jara (Cistus ladaniferus), romero (Rosmarinus officinalis), cantueso (Lavándula ssp.), tomillo (Timus ssp.).... El arbolado es de encina (Quercus ilex), quejigo (Quercus faginea) y Enebro (Juniperus communis); como excepcionalidad se ha observado algún ejemplar muy aislado de sabina (Juniperus turifera).

-Los herbazales, con manchas de carrizo y otra vegetación especializada, ligados a la zona influenciada por la humedad edáfica que se origina en las depresiones que acogen las lagunas.

\section{Fauna}

El llano cerealista en que se ubica la actuación, constituye un ecosistema artificial que alberga unas comunidades faunísticas muy simples. En él, la mecanización de las labores agrícolas produce una uniformación de los espacios físicos marginales -linderos, taludes, lomas, etc.- y la consiguiente merma en los efectivos de ciertas especies animales, por ejemplo, la liebre común (Lepus capensis). Asimismo el empleo masivo de herbicidas e insecticidas provoca la desaparición de numerosos insectos, lo que produce importantes repercusiones en la fauna ornítica (entre ellas codorniz, perdiz y otras) que pasan por una fase insectívora en las fases jóvenes de su crecimiento.

En la actualidad pueden encontrarse en la zona, como especies más relevantes la perdiz (Alectoris rufa), la codorniz (Coturnix), la liebre (Lepus timidus), el aguilucho cenizo (Circus pygardus) y el halcón peregrino (Falco peregrinus); además la bibliografía consultada señala la 

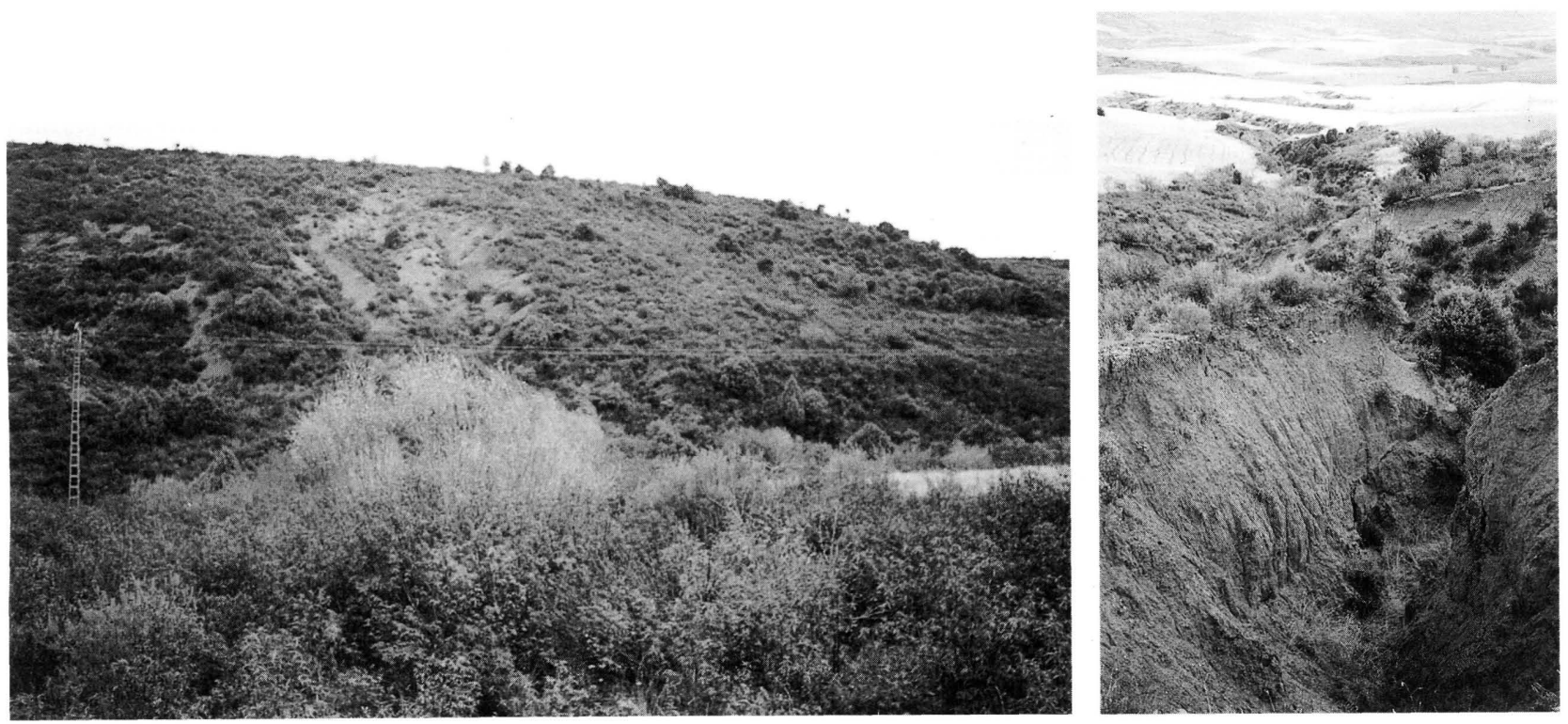

Foto 7.- La erosión es activa en aquellas zonas en pendiente donde la vegetación es incapaz de sujetar el suelo.

presencia de especies tan importantes y amenazadas de extinción como la avutarda o avetarda (Otis tarda) y el sisón (Otis tetrax), aunque nosotros no hemos podido constatarlo.

A estas especies se añade la abundante fauna antropófila que puebla la zona, integrada por diversas especies ubicuistas y oportunistas: gorriones, urracas, cuervos, vencejos, milanos, roedores, etc.

Por último debe citarse, por su papel en relación con la fauna, la existencia de las dos pequeñas lagunas endorreicas, de escasa profundidad, con cierto valor como área de parada de aves acuáticas migratorias. Se encuentran situadas a unos $4 \mathrm{~km}$. noreste del nuevo aeródromo, y precisamente alineadas con las pistas del aeródromo existente, afectadas, por tanto, en la actualidad por el tráfico de éste, lo que tiene interesantes repercusiones en la evaluación del impacto ambiental del proyecto. La bibliografía atribuye a estas lagunas una superficie aproximada de $100 \mathrm{Ha}$, pero en la actualidad el área inundada es mucho más baja -variable según las lluviasa causa de una serie de años de penuria hidrológica; no obstante la depresión topográfica que las alberga tiene un extensión considerable, constantemente mermada por la invasión de los cultivos colindantes. La bibliografía cita su utilización por las siguientes especies: Anade Real (Anas platyrhynchos), Porrón Común (Aythya ferina), Cerceta Pardilla (Marmaronetta angustirrostris), Pato Colorado (Netta rufina), Grulla (Grus), Ansar común (Anser), Avefría (Vanellus) y Focha común (Fulica atra), aunque dicha utilización hoy día es dudosa dada su escasísima extensión, sometidas a un retroceso que parece inexorable, sin apenas presencia de aves en sus inmediaciones, conformando un espacio natural en vías de desaparecer.

\section{Paisaje: Unidades paisajísticas}

Entendemos por paisaje lamanifestación externadel medio, perceptible, de forma polisensorial y subjetiva, por un observador.

El inventario relativo al paisaje se ha realizado sobre los parámetros que aportan mayor información sobre el previsible impacto del proyecto. Son éstos labase paisajística, y la intervisibilidad del territorio, concretada, a su vez, en el potencial de vistas (posibilidad de ver) y la incidencia visual (posibilidad de ser visto) (Fotos 9, 10 y 11).

La base paisajística, queda determinada por la estructura y textura del medio; la primera puede asociarse a las líneas maestras que definen la morfología del territorio: plataformas planas cortadas por barrancos. La textura está constituida por un tejido de parcelas grandes y un retículo de vegetación natural asociada a los barrancos, los linderos, los ribazos y algunos ejemplares arbóreos que aparecen aislados sobre los cultivos. Ambos elementos, formas y recubrimiento vegetal, permiten identificar como unidades de paisaje la plataforma ocupada por la estepa cerealista y los barracos con sus laderas más o menos forestadas y erosionadas; a ellas puede añadirse laurbanización próxima, con una expresión externa obviamente diferente

El potencial de vistas resulta relevante en los bordes de la plataforma en que se instala el futuro aeródromo, porque constituyen cornisas de vistas desde las que se percibe un horizonte profundo, amplio y bello. La situación de borde 


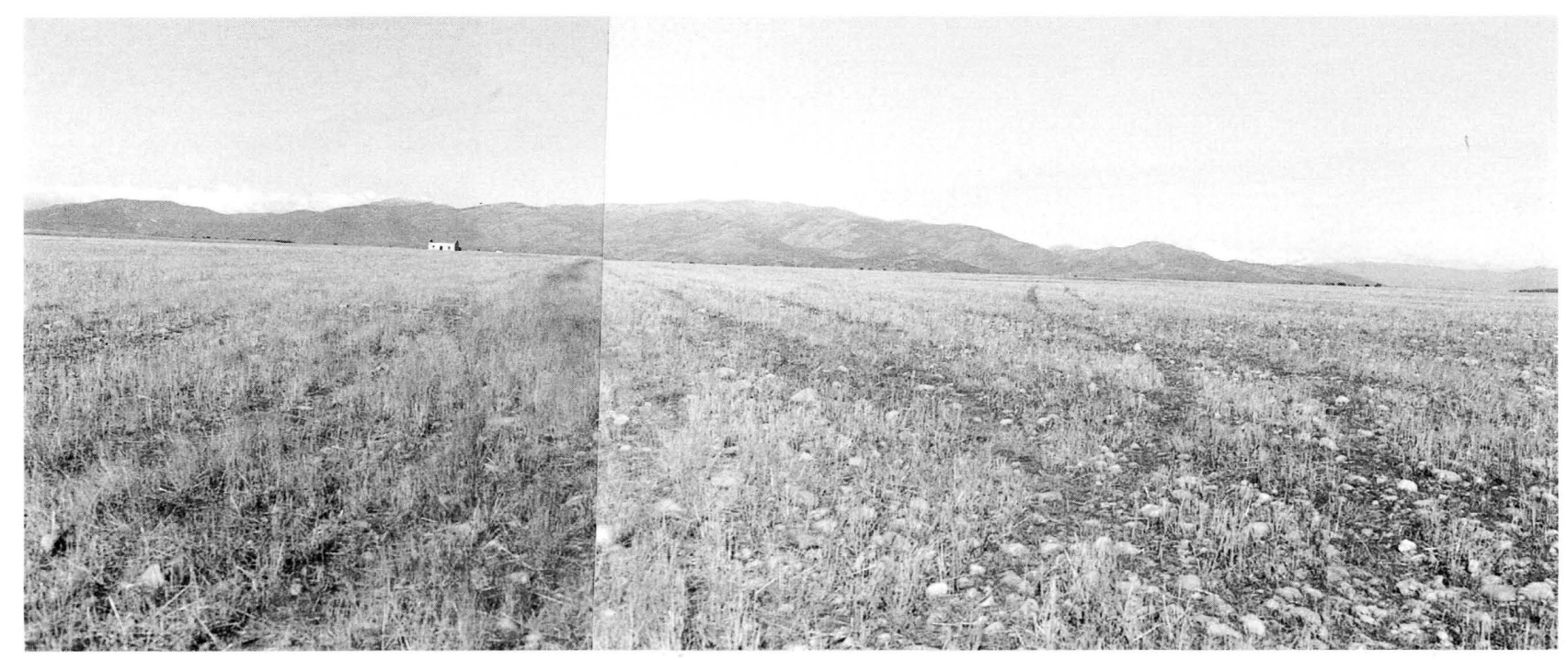

Foto 9.- Horizonte lejano, limite definitivo de la cuenca visual, que enriquece el potencial de vistas.
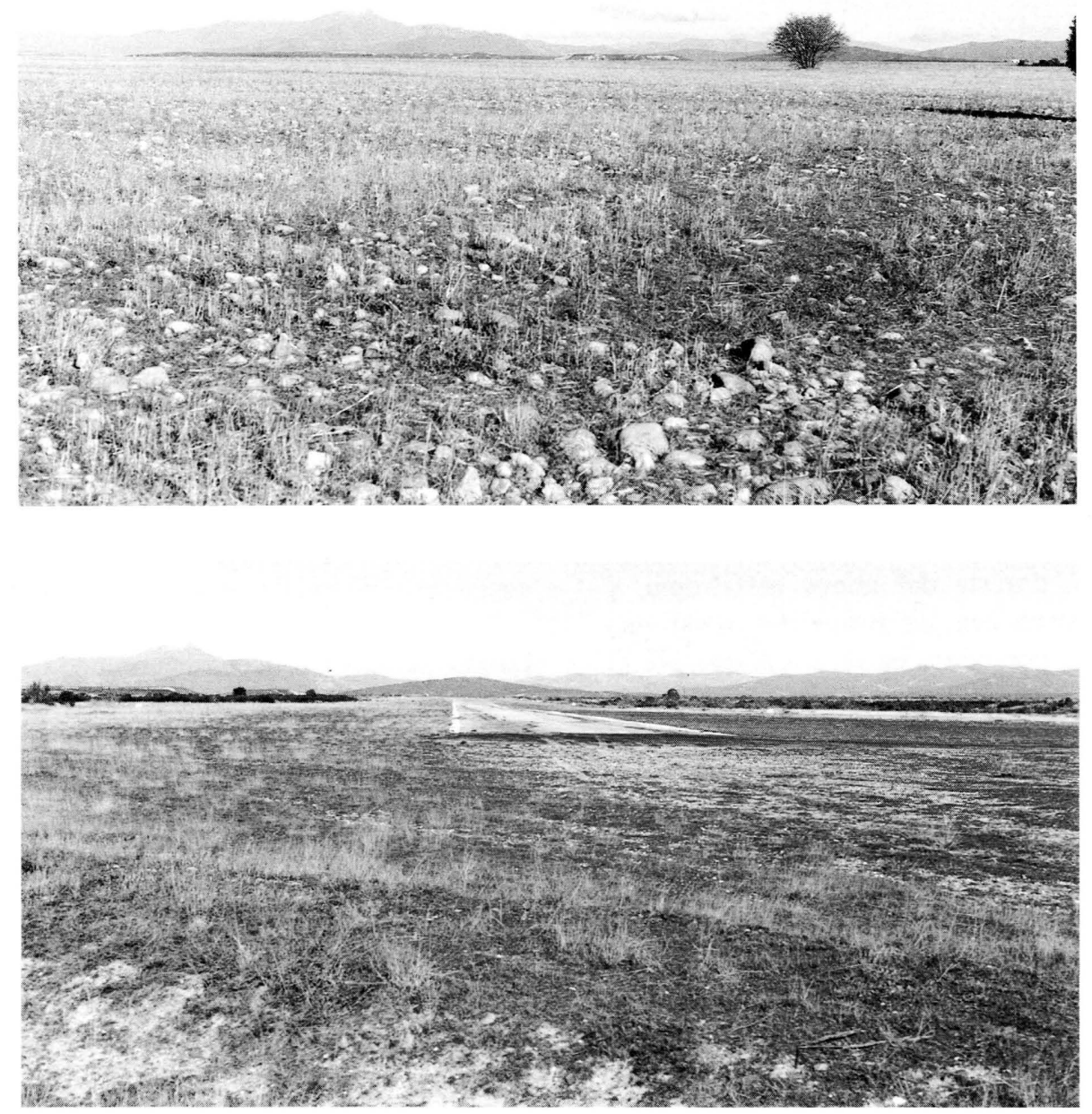

Foto 10.- Muestra el potencial de vistas de una cuenca cuya dimensión es notable por la profundidad y amplitud del campo de visión y por la calidad del tema de las vistas (perfil serrano en este caso). En la foto inferior se aprecia el extremo de la pista existente y muestra la escasa incidencia visual de este tipo de actuaciones absorbidas fácilmente por la horizontalidad del páramo, asi como la escas a calidad intrinseca de éste. 

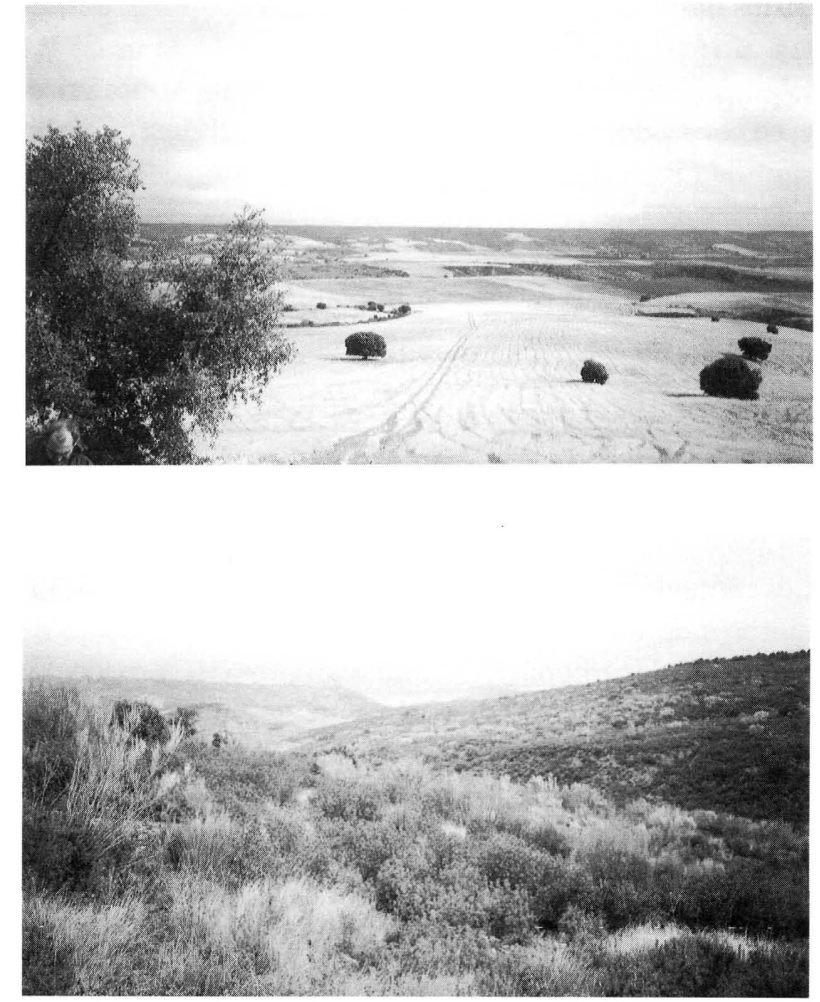

Foto 11.- Aspecto de la cuenca visual mostrando el movimiento y la diversidad de elementos. Se puede observarla horizontalidad del páramo de raña y las laderas de los valles que la drenan.

de las citadas cornisas y la dirección de sus vistas hacia el exterior de la plataforma, supone un nula afección por los edificios e instalaciones proyectadas.

Por el contrario, el carácter plano de la plataforma, cuya visibilidad se limita al primer plano, dota al paisaje de una baja incidencia visual (capacidad de ser visto), de tal manera que absorbe muy bien los edificios y la pista, los cuales sólo se verán desde distancias cortas, determinando, así, una reducida cuenca visual.

\section{Características socioeconómicas}

Se trata de un área rural profunda, deprimida y en declive, con una acusada falta de actividad, que ve en el aeródromo la actividad capaz de frenar la sangría de hombres que la azota.

El municipio que la acoge, según los datos del Censo de Población está en regresión poblacional, resultado de un progresivoabandono del campo, que, aunque generalizable a la práctica totalidad de las zonas rurales, resulta particularmente agudo aquí. La densidad de población es el $15,4 \%$ de la media nacional y el $8,2 \%$ de la población de la Unión Europea. Puede, por tanto, considerarse que, siendo la densidad límite establecida para definir la

\begin{abstract}
"desertización humana" $13 \mathrm{Hab} / \mathrm{km}^{2}$, la zona estudiada está incluida dentro de aquella clasificación.

Se trata de una zona eminentemente agraria con monocultivo de cereal de secano, donde el único ganado de renta importante es el lanar, actualmente en retroceso; resultan insignificantes los efectivos de vacuno, caprino y porcino.
\end{abstract}

\section{Patrimonio histórico artístico}

No se tiene constancia sobre la existencia de algún tipo de recurso arqueológico, histórico, arquitectónico o de cualquier otro tipo en la zona afectada por el aeródromo.

\subsection{Acciones del proyecto susceptibles de producir impacto}

El método de identificación de impactos que se utiliza consiste en determinar primero las acciones del proyecto que pueden desencadenar incidencias en su entorno, señalar después los factores ambientales susceptibles de ser alterados, para concluir por fin con la búsqueda de relaciones causa-efecto, cada una de las cuales identifica un impacto.

Para el aeródromo se distinguen dos fases temporales en las que se producen impactos: construcción y funcionamiento.

1. Fase de construcción: pista, edificios y aparcamientos.

1.1 Excavaciones.

1.2 Transporte, carga, descarga de materiales.

2. Fase de funcionamiento.

2.1 Presencia de edificios e infraestructuras.

2.2 Presencia de obras auxiliares.

2.2.1 Señalización.

2.2.2 Cerramientos

2.2.3 Iluminación.

2.3 Tráfico aéreo.

2.3.1 Emisión de ruido por avionetas.

2.3.2 Emisión de contaminantes atmosféricos.

2.4 Tráfico terrestre.

2.4.1 Emisión de ruidos por vehículos.

2.5 Tratamientos de mantenimiento de pistas.

2.6 Vertidos incontrolados o accidentales de sustancias contaminantes.

2.7 Riesgo de accidentes.

\subsection{Factores ambientales susceptibles de recibir un impacto significativo}

Los factores ambientales relevantes, que permiten definir las consecuencias ambientales del proyecto del nuevo aeródromo son los que se indican a continuación. 
1. Medio Físico.

1.1 Atmósfera.

1.1.1 Calidad del aire

1.1.2 Ruido.

1.2 Agua.

1.2.1 Acuíferos subterráneos.

1.3 Suelo

1.3.1 Edafología.

1.4 Procesos.

1.4.1 Erosionabilidad del suelo.

1.4.2 Compactación del suelo.

\section{Medio biótico.}

2.1 Flora y vegetación.

2.1.1 Cultivos cerealistas.

2.1.2 Formaciones de matorral pluriespecífico.

2.2 Fauna.

2.2.1 Comunidad de aves acuáticas.

2.2.2 Otras aves

3. Paisaje

3.1 Visibilidad

3.2 Paisaje intrínseco.

\section{Medio socioeconómico.}

4.1 El hombre

4.2 Población.

4.3 Empleo.

4.4 Servicios e infraestructuras.

4.5 Servicios y equipamiento social.

4.6 Carreteras y vías de comunicación.

4.7 Aceptación social.

\subsection{Relación, descripción y caracterización de impactos}

Cruzando las acciones y los factores antes indicados en forma de matriz (Tablas 2 y 3 ) se obtienen los impactos del proyecto sobre las casillas de cruce en que se produce una interacción. En una primera fase se han identificado numerosos impactos, aun a sabiendas de que muchos de ellos pueden ser no significativos, para someterlos después a un cribado que, de forma justificada, permita detenerse en los que realmente pueden tener repercusiones en la aceptación, modificación o rechazo del proyecto.

\section{Sobre la atmósfera: calidad del aire}

Los trabajos de desbroce, despeje y movimientos de tierra, quema de residuos vegetales, transporte y descarga de materiales, etc., emiten partículas (polvo, humos, gases de escape y otros contaminantes atmosféricos) que alteran los niveles de inmisión. Se trata de efectos locales y de carácter temporal, lo que añadido a la alta ventilación de la zona y a los mínimos niveles de inmisión de que se parte, permiten afirmar que tales niveles permanecerán lejos de los tolerados por laLey de Protección del Ambiente Atmosférico, $y$, en consecuencia, calificar el impacto resultante como no significativo

Durante la fase de funcionamiento del aeródromo, el incremento en los niveles de inmisión puede provenir de distintas fuentes. Las más importantes son:

-Gases de escape de los motores de los aviones.

-Escapes de los motores de los vehículos de los empleados y visitantes del aeródromo.

Los contaminantes contenidos en los gases de escape de los motores de los aviones se componen principalmente de monóxido de carbono ( $\mathrm{CO}$ ), hidrocarburos ( $\mathrm{HC})$, óxidos de nitrógeno $\left(\mathrm{NO}_{x}\right)$, hollín y otras materias en forma de partículas sólidas. Los gases de escape también contienen ácidos orgánicos altamente irritantes y componentes de carbono y azufre. La cantidad de estos compuestos arrojados a la atmósfera es función del tipo de avión y de su motor, de la fase y modo de operación, y del tiempo en que opera en cada fase de operación (rodaje o ralentí, despegue, subida, aproximación, aterrizaje, ..). Por las mismas razones expuestas para la fase de construcción (niveles de inmisión mínimos en la situación preoperacional y alta capacidad dispersante de la atmósfera en la zona) consideramos este efecto como moderado.

Alteración del confort sonoro: ruido

La emisión de ruido, es uno de los impactos típicos que se asocian a las maniobras de las aeronaves en los aeródromos. El hecho de que exista una urbanización de segunda residencia en las proximidades de emplazamiento previsto, hace que deba dedicarse a este impacto una particular atención.

Los modelos de avión que utilizarán las instalaciones previstas son todos ellos de hélice (la mayor parte avionetas de escuela) y turbohélice (Tablas 3 y 4). En éstos, las fuentes sonoras son las aspas en su movimiento de rotación, la rodadura por la pista y los motores en funcionamiento.

Para el cálculo del impacto del ruido en el entorno se ha empleado un programa informático, el INM (Integrated Noise Model) versión 4.11, desarrollado a partir de 1992 por el John A. Volpe Center National Transportation Systems Center (Volpe Center) en colaboración con la Federal Aviation Administration (F.A.A). Este programa es de uso general para el estudio de la contaminación acústica, tanto de grandes como de pequeños aeropuertos y aeródromos. Asimismo, aparece recogido en el Anexo 16 (Protección del medio ambiente) de las normas y métodos recomendados por la $\mathrm{OACI}$ (Convenio sobre Aviación Civil Internacional). 


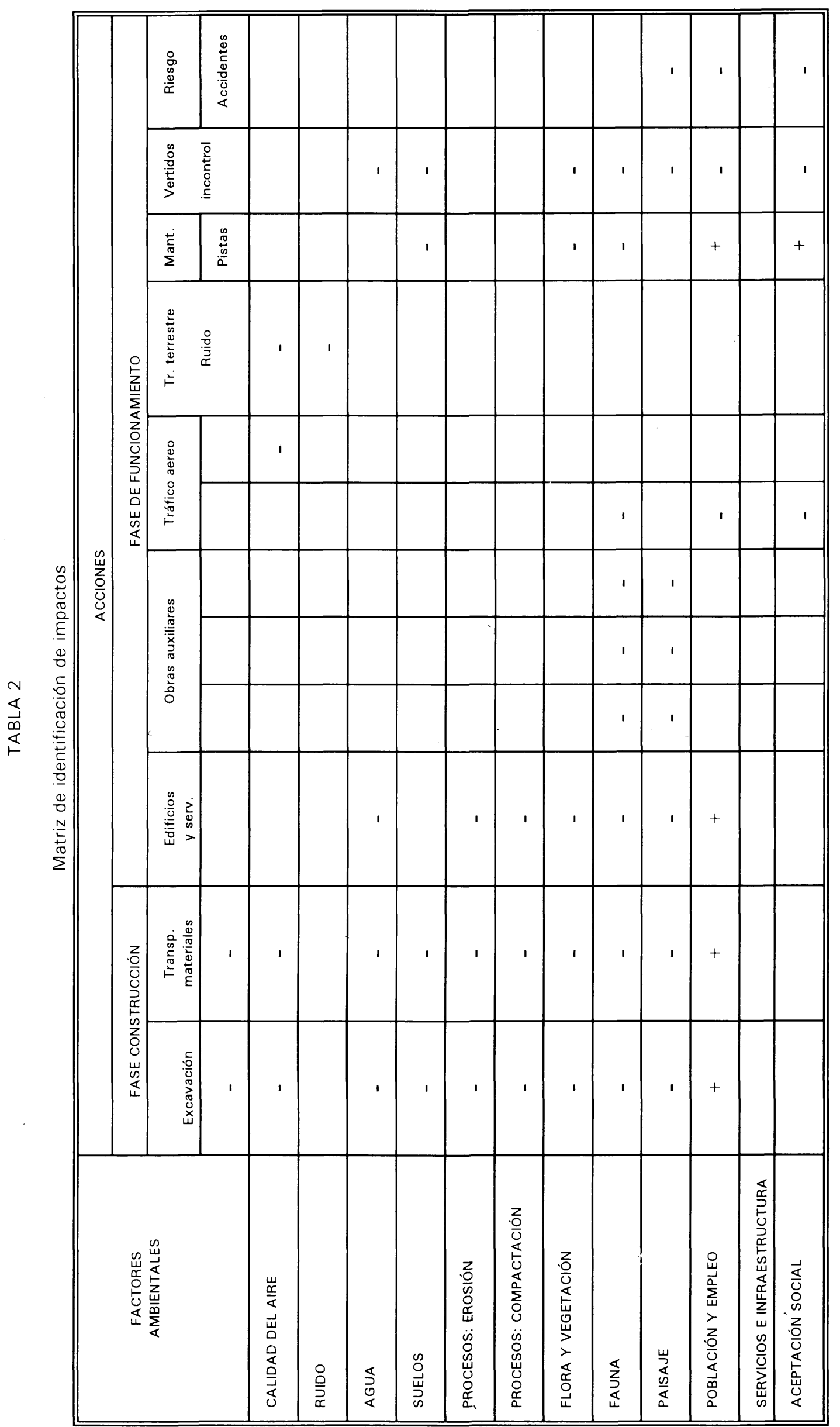

0
2
0
0
0
0
+
1
0
2
0
0
2
1
1
0
00
0
0
0
0
0 
TABLA 3

\begin{tabular}{||l|l|c||}
\hline \multicolumn{3}{|c||}{ TIPO DE AVIONES } \\
\hline \multicolumn{1}{|c||}{ Tipos de aviones } & \multicolumn{1}{|c||}{ Marca/Modelo } & \multicolumn{1}{|c||}{ Ruido } \\
\hline Ligeros de Escuela & Cessna 152 & $65,8 \mathrm{~dB}(\mathrm{~A})$ \\
Medios de Escuela & Piper PA-28-R-200 & $75,5 \mathrm{~dB}(\mathrm{~A})$ \\
Bimotores de Escuela & Piper PA-34-200-T & $78,6 \mathrm{~dB}(\mathrm{~A})$ \\
Turbo-hélices & Casa C-212-CC & $87,6 \mathrm{~dB}(\mathrm{~A})$ \\
Turbo-hélices & Cessna 425 & $75,0 \mathrm{~dB}(\mathrm{~A})$ \\
Turbo-hélices & Saab Fairchild-340 & $79,3 \mathrm{~dB}(\mathrm{~A})$ \\
Aviones pesados & Lockeed L-100-30 & $98,0 \mathrm{~dB}(\mathrm{~A})$ \\
\hline
\end{tabular}

TABLA 4

Tráfico de aviones

\begin{tabular}{||c|c|c|c|c|c||}
\hline Horario & $\begin{array}{c}\text { Aviones } \\
\text { Ligeros } \\
\text { Escuela }\end{array}$ & $\begin{array}{c}\text { Aviones } \\
\text { Medios } \\
\text { Escuela }\end{array}$ & $\begin{array}{c}\text { Aviones } \\
\text { Bimotores } \\
\text { Escuela }\end{array}$ & $\begin{array}{c}\text { Turbo } \\
\text { Hélices }\end{array}$ & $\begin{array}{c}\text { Aviones } \\
\text { Pesados }\end{array}$ \\
\hline \multicolumn{7}{|c|}{ Despegues y tomas B-M-A } \\
\hline De 9 a 10 & $5-6-7$ & $0-1-2$ & $0-0-0$ & $0-0-0$ & $0-0-0$ \\
\hline De 10 a 11 & $7-8-8$ & $1-2-2$ & $0-1-1$ & $0-0-0$ & $0-0-0$ \\
\hline De 11 a 12 & $2-2-3$ & $2-2-2$ & $1-1-1$ & $0-0-0$ & $0-0-0$ \\
\hline De 12 a 13 & $2-2-3$ & $2-2-2$ & $2-2-2$ & $1-0-1$ & $0-0-0$ \\
\hline De 13 a 14 & $1-2-2$ & $2-3-3$ & $2-3-3$ & $0-0-0$ & $1-1-1$ \\
\hline De 14 a 15 & $2-2-2$ & $1-1-1$ & $1-1-1$ & $0-0-1$ & $0-0-0$ \\
\hline De 15 a 16 & $4-4-4$ & $2-2-2$ & $2-2-2$ & $0-0-1$ & $0-0-0$ \\
\hline De 16 a 17 & $6-7-8$ & $3-3-3$ & $2-2-2$ & $0-0-0$ & $0-0-0$ \\
\hline De 17 a 18 & $7-7-8$ & $3-3-3$ & $2-2-2$ & $0-1-1$ & $0-1-0$ \\
\hline De 18 a 19 & $6-7-7$ & $2-2-2$ & $1-1-1$ & $0-0-1$ & $0-0-0-$ \\
\hline De 19 a 20 & $2-3-3$ & $1-1-1$ & $1-1-1$ & $0-0-1$ & $0-0-0$ \\
\hline de 20 a 21 & $2-2-2$ & $1-1-1$ & $1-1-1$ & $0-0-1$ & $0-0-0$ \\
\hline De 21 a 22 & $1-1-1$ & $1-1-1$ & $1-1-1$ & $0-0-0$ & $0-0-0$ \\
\hline \hline
\end{tabular}

B: Mínimo; M: Medio; A: Máximo

Basándose en los datos sonoros proporcionados por las pruebas de homologación de los diferentes modelos de aviones que utilizaran el aeródromo, o similares, y el tráfico previsto, el programa estima el Nivel de Ruido Efectivo EPNdB (Effective Percived Noise Level: Nivel de Ruido Efectivo Percibido), producido por cada tipo de avión, dato básico para la determinación de cualquier índice que refleje las molestias que se pueden causar a la población residente en el ámbito de referencia. Con ello y con los datos topográficos y climáticos que se le proporcionan, y para unas rutas determinadas de las operaciones de despegue, aterrizaje y maniobras inmediatas, el programa calcula la disipación del sonido con la distanciay, con todo ello, construye curvas isófonas para diversos 
indicadores representativos de las molestias a la población. Tratándose de un aeródromo dichos indicadores han sido:

-NEF: Noise Exposure Forecast-Predicción de la exposición al ruido

-Leq.dB(A): Nivel de Ruido Equivalente en decibelios A.

El primero es el más utilizado para el cálculo de la exposición al ruido producido por el tráfico aéreo, mientras el segundo es de empleo general en todo tipo de actividades y aparece recogido en la legislación española.

Ambos métodos de análisis sobrevaloran aquellas bandas de frecuencia que resultan más molestas para el oído humano (generalmente las bandas más altas) y consideran, no sólo el nivel de ruido, sino también la frecuencia de exposición (se ha demostrado que resultan más nocivos para la salud aquellos sonidos más frecuentes aunque sean de menor intensidad).

Los niveles de diagnóstico a partir del NEF son los siguientes:

\section{$\mathrm{NEF}<=20 \quad$ No hay quejas.}

$20<\mathrm{NEF}<=25$ Algunas quejas esporádicas.

$25<\mathrm{NEF}<=3$ Algunas quejas porque el ruido puede interferir alguna actividad.
$30<\mathrm{NEF}<=35$ Existe posibilidad dequejas individualizadas y acciones comunitarias.

$35<\mathrm{NEF}<=40$ Se producirán quejas individualizadas y acciones comunitarias.

$40<\mathrm{NEF} \quad$ Inaceptable para la comunidad

Para el Leq.dB(A) se establecen las siguientes categorías:

$\begin{array}{ll}\text { Leq }<40 & \text { Idílico. } \\ 40<\text { Leq }<=50 & \text { Bueno. } \\ 50<\text { Leq }<=60 & \text { Aceptable. } \\ 60<\text { Leq }<=70 & \text { Tolerable. } \\ \text { Leq }>70 & \text { Intolerable }\end{array}$

La legislación establece en un Leq de $65 \mathrm{~dB}(\mathrm{~A})$ el límite legal en zonas residenciales.

Para evaluar el efecto de la emisión de ruidos sobre el entorno, se ha calculado la siguiente serie de curvas isofónicas (“isoNEF” e “isoLeq):

$\begin{array}{lccccccc}\text { NEF } & 15 & 20 & 25 & 30 & 35 & 40 & 45 \\ \text { Leq } & 50 & 60 & 65 & 70 & 80 & & \end{array}$

En todos los casos, estas curvas han sido calculadas para las peores condiciones atmosféricas y mayor sobrecarga de tráfico.

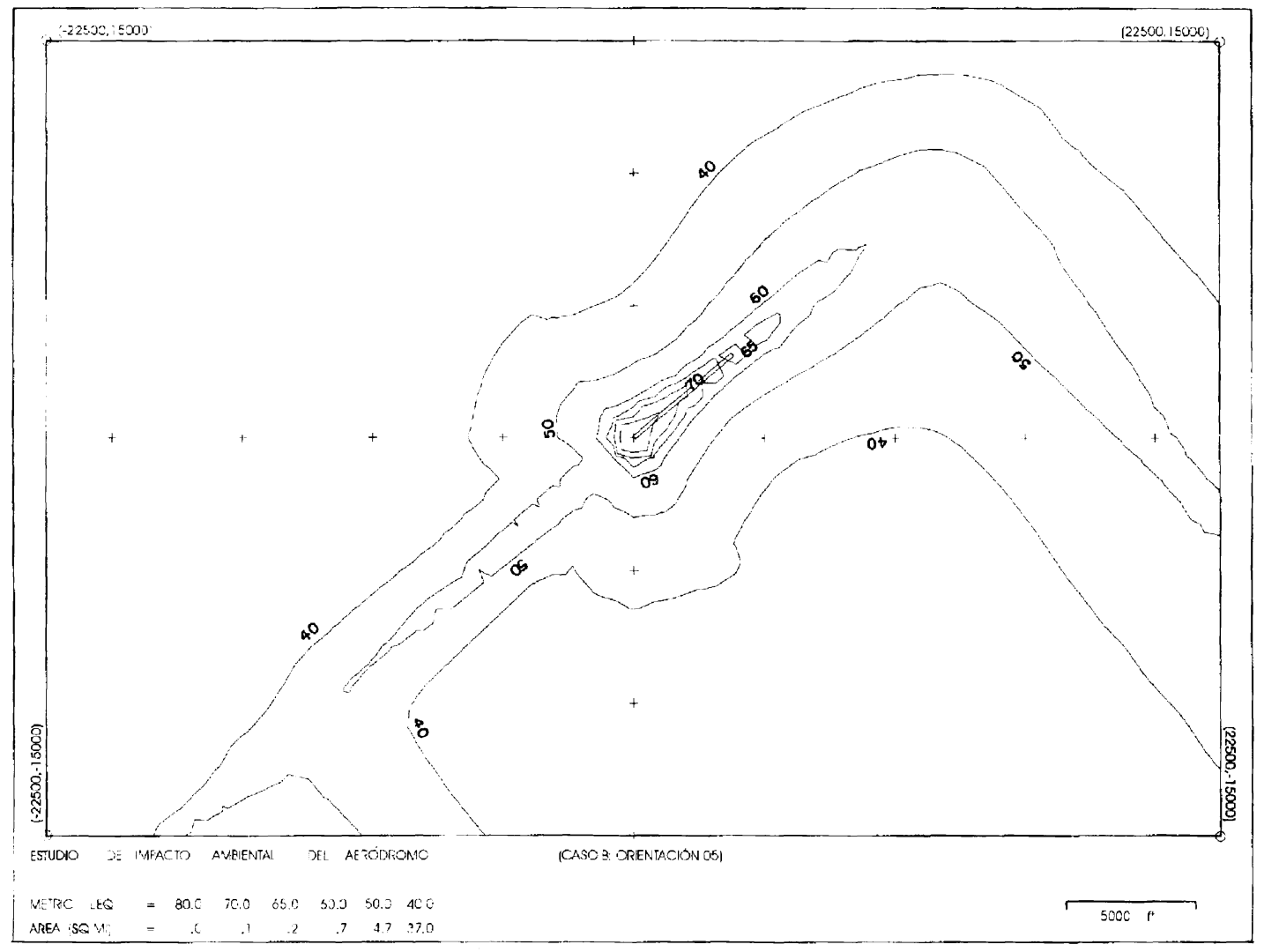

Fig. 4.- Ejemplo de las huellas sonoras: líneas isófonas (Caso B). 


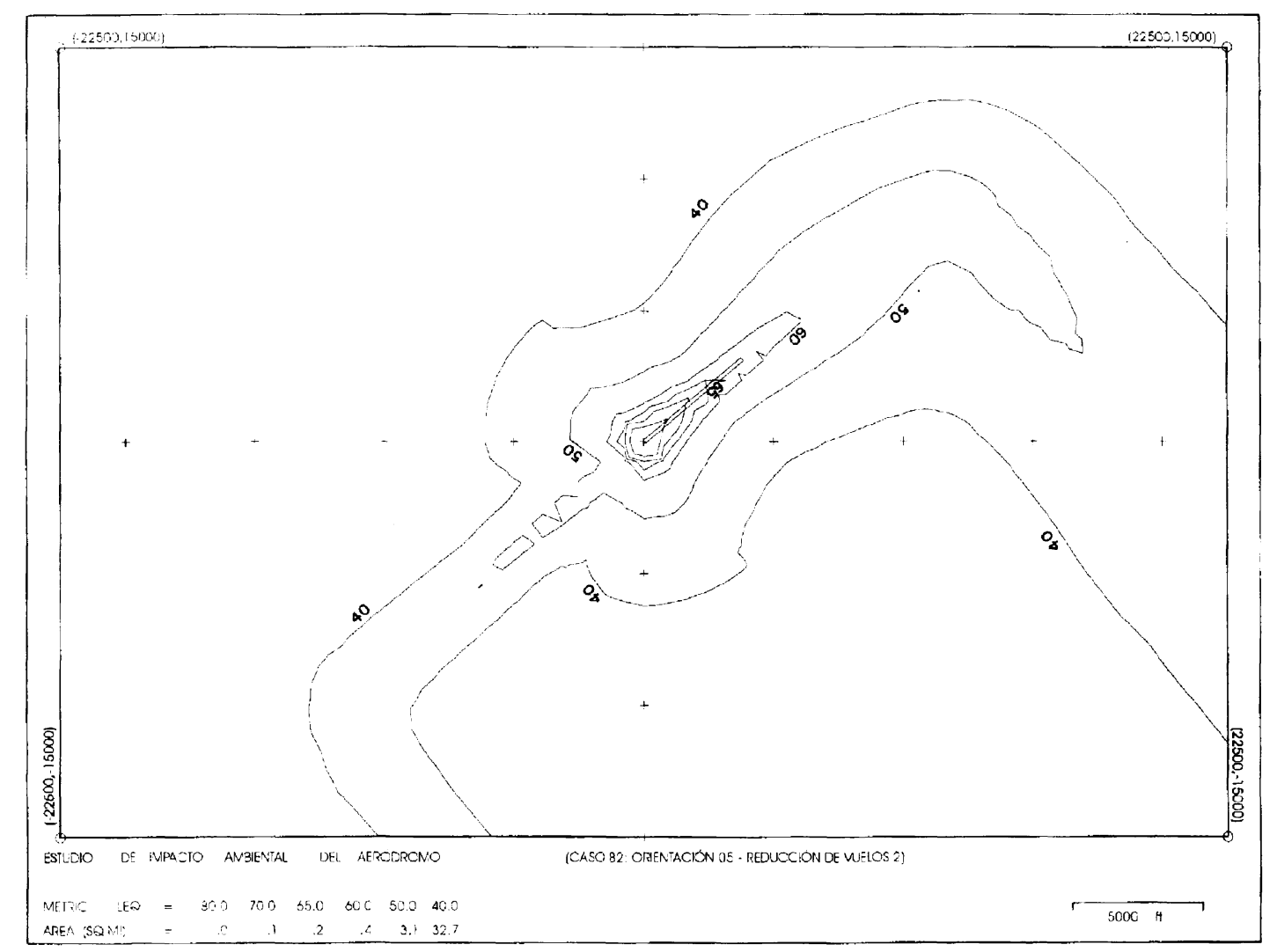

Fig. 5.- Ejemplo de las huellas sonoras: lineas isófonas (Caso B2).

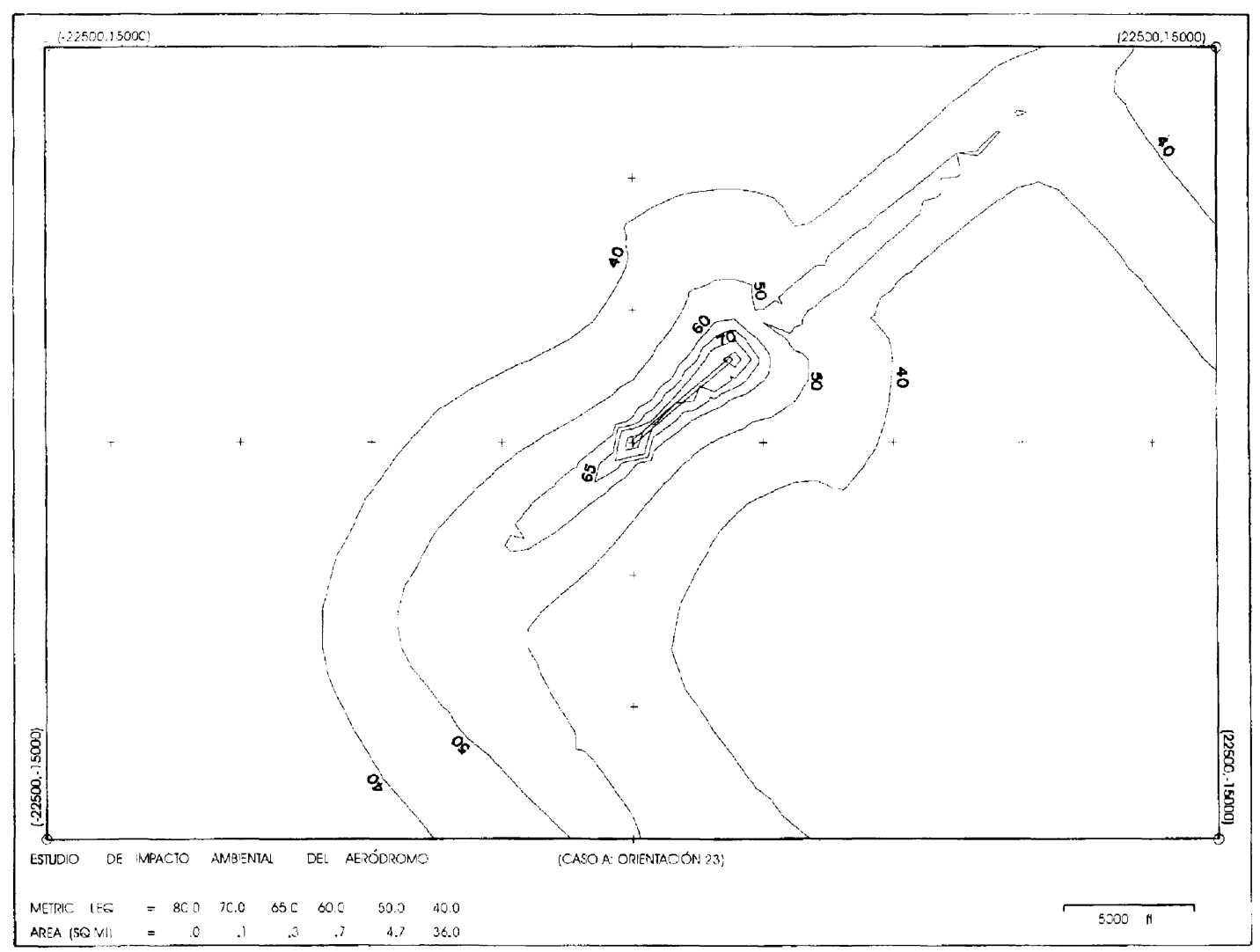

Fig. 6.- Ejemplo de las huellas sonoras: lineas isófonas (Caso A). 
Las Figuras 4, 5 y 6 muestran varios ejemplos de las líneas isófonas dibujadas por el programa: Aplicando a ellas los niveles de diagnóstico antes indicados, se obtiene inmediatamente una valoración de los impactos, y en particular los posibles puntos conflictivos. Se concluye, con ello, que el impacto producido por la emisión de ruido del aeródromo se considera aceptable.

\section{Efectos sobre el agua}

El escaso interés hidrogeológico de la zona y la poca significación de los cursos de agua en las inmediaciones, permiten calificar la posibilidad de contaminación de las aguas como remota. En todo caso se prevé como medida preventiva la dotación de los sistemas de recogida necesarios para evitar la posibilidad de que lleguen al terreno libre los vertidos de la zona de repostado y de mantenimiento y limpieza de los aviones.

\section{Efectos sobre los suelos}

En la fase de construcción, las obras de excavación, rellenado, explanación, etc. y en general, todas las operaciones de movimiento de tierras, juntoal recubrimiento asfáltico de la pista, consumen un suelo de tradicional utilización agrícola.

El potencial agronómico del suelo es escaso, (Clase Agrológica III, correspondiente a agricultura extensiva), la superficie afectada por la actuación es de $132 \mathrm{Ha}$, de la cual sólo una parte es directamente ocupada por pista, edificios e instalaciones; por otra parte se prevé retirar los suelos vegetales para ser reutilizados en el tratamiento posterior de las zonas afectadas. Todo ello unido a las dificultades climáticas (heladas, escasez de lluvias, etc.) y a la situación de abandono progresivo en que se encuentra la agricultura (a consecuencia de los excedentes comunitarios), permiten calificar el impacto de insignificante, y según la terminología del reglamento de EIA, como compatible.

\section{Afecciones a la vegetación}

La actuación solamente afecta a la estepa cerealista ubicada en el páramo, ecosistema artificial, no raro, nada diverso, de muy bajo valor ecológico, por tanto; todo ello supone que este impacto sea despreciable.

Las zonas de más interesante vegetación, ligadas, como se dijo, a los cursos de agua, donde se refugia la vegetación relíctica del antiguo bosque que pobló la zona, no son afectadas por el proyecto.

\section{Afecciones a la fauna}

El tráfico aéreo puede afectar a la poblaciones de aves migratorias que sobrevuelen las inmediaciones del futuro aeródromo, lo cual representa, a su vez, un peligro de colisión para las aeronaves. No obstante, el hecho de que la mayor parte de los aparatos son de hélice, el ruido y la velocidad permiten a las aves conocer y predecir el peligro y alejarse de él. De este modo al iniciar el recorrido por las pistas las aves tienen tiempo de elevar su vuelo y apartarse de la trayectoria del aeroplano; los impactos con aves durante el vuelo, lejos del aeródromo, son más difíciles y, en todo caso, podrían detectarse los bandos en emigración mediante el radar y delimitarse los períodos, rutas y alturas que siguen las aves.

A pesar de ello parece razonable prever en el proyecto algún sistema que ahuyente las aves, evitando así los peligros que, tanto para ellas como para las aeronaves, representa la colisión.

\section{Alteraciones sobre el paisaje}

El impacto sobre el paisaje dependerá de la envergadura, materiales, diseño, etc. de los edificios e instalaciones que se realicen, de la calidad intrínseca de las unidades de paisaje a que afecte y de la intervisibilidad.

La calidad paisajística de la unidad donde se sitúa la actuación, apenas afecta al paisaje, puede incluso enriquecerlo si se ordenan las diferentes zonas y se revegetan los espacios no ocupados por infraestructuras o edificaciones.

El valor final del paisaje va a depender de la calidad de lo construido, es decir de la adecuación del proyecto al entorno mediante un cuidadoso diseño y ejecución, acabado, cierres, texturas, etc. De esta forma cambia el carácter del paisaje, pero no su valor.

La obra se califica como de baja incidencia visual, de tal manera que sólo se percibe desde una cuenca visual reducida, como corresponde al carácter plano de la superficie en que se ubica, capaz de absorber fácilmente a la actuación prevista.

\section{Impacto sobre población y empleo}

La despoblación del agro se considera en las regiones interiores de España, uno de los principales problemas ambientales, dado el papel del agricultor en la conservación de importantes factores ambientales: suelo, vegetación, paisaje, patrimonio histórico y cultural, etc. La zona sufre este proceso. El aeródromo va a suponer la introducción de una nueva actividad en un área deprimida que se degrada precisamente por falta de inversiones e iniciativas económicas. Este impacto se califica como beneficioso.

El empleo generado, en total, supone 252 efectivos, de los cuales puede estimarse en unos 50 los que pueden ser 
cubiertos por la población del entorno próximo; esto contribuye a fijar la población en la comarca e incluso a aumentarla, lo que ambientalmente se considera positivo.

\section{Afecciones a los servicios e infraestructuras}

El aeródromo contribuirá a mejorar los servicios y equipamientos sociales de la comarca, estimulando la capacidad de iniciativa y atractivo de la zona para la localización de actividades económicas.

Aceptación social

La población está impaciente porque se inicie la construcción del aeródromo, en el que ven una de las escasísimas posibilidades de promoción económica y social.

\section{VALORACIÓN DE IMPACTOS}

De acuerdo con el Reglamento de EIA (R.D. 1131/88) y teniendo en cuenta la descripción antes realizada y la caracterización de la Tabla 5 , se valoran los impactos en los términos siguientes:

Impacto ambiental compatible: Aquel cuya recuperación es inmediata, tras el cese de la actividad, y no necesita prácticas protectoras o correctoras.

Impacto ambiental moderado: Aquel cuya recuperación precisa protectoras o correctoras intensivas, y en el que la consecución de las condiciones ambientales iniciales requiere cierto tiempo.

Impacto ambiental severo: Aquel en el que la recuperación de las condiciones del medio exige la adopción de medidas protectoras o correctoras, y en el que, aún con esas medidas, la recuperación precisa un tiempo dilatado.

Impacto ambiental crítico: Aquel cuya magnitudes superior al umbral aceptable. Con él se produce una pérdida permanente de la calidad de las condiciones ambientales, sin posible recuperación, incluso con la adopción de medidas protectoras o correctoras.

De acuerdo con todo ello los impactos descritos se valoran como se indica en la citada Tabla 5.

\section{MEDIDAS CORRECTORAS}

Una vez que se han identificado y valorado los impactos más característicos como consecuencia de la implantación y uso del futuro aeródromo, se describen a continuación una serie de medidas preventivas y correctoras de la influencia medioambiental que implica la realización del Proyecto evaluado, cuyo objeto es minimizar los impactos negativos que no puedan ser evitados durante la construcción y posterior funcionamiento del aeródromo y que al mismo tiempo aproveche al máximo las nuevas oportunidades que ofrece el espacio en cuestión.

\section{Sobre la calidad del aire}

Durante la fase de funcionamiento del aeródromo, la causa del incremento en los niveles de inmisión provienen fundamentalmente de los gases de escape de los motores de los aviones, especialmente de monóxido de carbono ( $\mathrm{CO}$ ) e hidrocarburos $(\mathrm{HC})$, los cuales son producto de las combustiones incompletas cuando los motores funcionan en ralentí o en baja velocidad en las maniobras de estacionamiento. Frente a este problema, sólo cabe seleccionar los modelos de aeronaves que incorporen inyectores de combustible y utilizar vehículos auxiliares que produzcan un mínimo nivel de contaminación para el estacionamiento de las aeronaves.

\section{Sobre el ruido}

Durante la fase de construcción se pueden hacer las mismas recomendaciones que hemos señalado en el apartado anterior: alejar de las zonas urbanizadas aquellas fuentes de ruido como el tráfico de maquinaría pesada, carga y descarga de materiales, etc.

Las medidas correctoras en la fase de funcionamiento se deberán aplicar en función del origen del ruido, es decir, en las fuentes de emisión, en la transmisión y operaciones implicadas, y en la recepción.

En las fuentes de emisión

-Elección del tipo de aeronaves menos ruidosas.

-Evitar que se sobrevuelen las inmediaciones de la urbanización próxima al aeródromo, así como de los pueblos del entorno.

-Limitar el tráfico aéreo de las aeronaves más pesadas cuando las condiciones climáticas obliguen a utilizar las rutas que producen mayor nivel de ruido sobre la urbanización, que es el punto más frágil para este tipo de contaminación.

La limitación del uso del suelo en los alredores del aeródromo para aceptar sólo los que sean compatibles con los niveles de ruido previsibles, son medidas que debe prever el planeamiento urbanístico.

La implantación en todas las zonas posibles del aeródromo, de una gran cobertura vegetal de grandes árboles ayudaría como elementos aislantes, además de proporcionar las ventajas propias de la vegetación. En todo caso, conjugando las soluciones de diseño de edificios y disposición de éstos con la formación de pantallas aislantes, protección vegetal y aislamiento de las ventanas puede conseguirse 


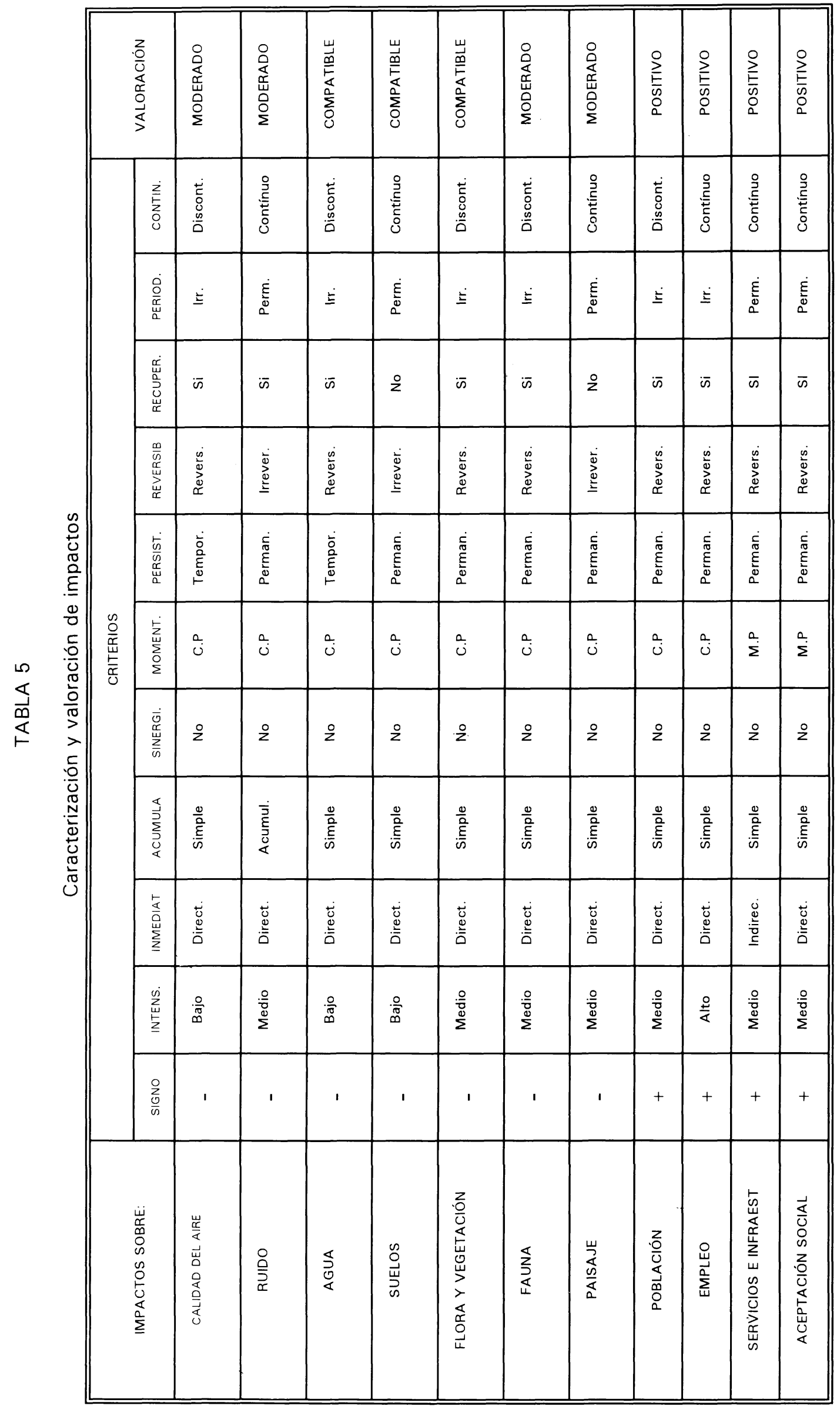


reducir el problema. En todos los casos las especies a utilizar en la cobertura vegetal deberán ser las mejor adaptadas a la zona, principalmente autóctonas, conforme al inventario expuesto en el apartado de flora y vegetación.

\section{Sobre el agua}

Debido a la reducida superficie ocupada por el complejo aeronáutico apenas tiene importancia la impermeabilización del terreno, al no verse afectados los mecanismos de recarga de los acuíferos, manteniéndose la tasa de infiltración en los niveles actuales.

En este caso, la única medida posible es la preventiva, evitando que se produzcan derrames y goteos de combustibles, escapes de depósitos de aceite y grasa, de detergentes enérgicos, etc. al suelo.

\section{Sobre suelos}

Las recomendaciones para proteger a los suelos se basan en la revegetación de superficies de suelo desnudo y en aprovechar para ello las "tierras vegetales". Se trata de retirar a un lugar previsto la capa de suelo fértil durante las operaciones de obra y construcción. Esta tierra vegetal, aparte de ser.suelo fértil originado in situ, y por consiguiente similar al existente en los alrededores, y colonizable por la vegetación autóctona, posee una gran cantidad de semillas y microfauna simbiótica con un elevado poder de autocolonización.

\section{Sobre flora y vegetación}

En este apartado no se requieren medidas correctoras propiamente dichas, al tratarse de una zona dedicada fundamentalmente al cultivo cerealista, de escasísimo interés ecológico. De todos modos, sería conveniente realizar plantaciones con especies autóctonas en las zonas libres de edificios o instalaciones.

\section{Sobre fauna}

Las medidas que se sugieren a continuación, tienden a reducir los posibles riesgos de colisión con las aves que puedan aparecer en las cercanías del aeródromo. Son las siguientes:

-Ahuyentar las poblaciones de aves de los conos de vuelo, mediante prácticas de cetrería, especialmente halcones o el empleo de figuras artificiales de estas rapaces.

-Emisión de ruidos mediante altavoces, instalación de algún tipo de alarma, o disparo sistemático de morteros de fogueo.

-Emisión de sonidos de alarma similares a los que emiten las propias aves.
-Emisión de campos de microondas

-Estudio y posterior manejo de los biotopos presentes en la zona de estudio, mediante:

la sustitución de plantas atractivas (cereal, girasol, etc.) por otras que no atraigan a las aves.

.establecer zonas acotadas que favorezcan la instalación de las aves más allá de los límites del aeródromo.

-Eliminación de cualquier presencia de basureros y otros focos de alimentación para las aves.

La adopción real de estas medidas se hará en finción de un seguimiento de las afecciones producidas a las aves.

\section{Sobre paisaje}

Se trata de integrar visualmente el aeródromo en su entorno:

-Revegetar las zonas libres y plantar alineaciones de árboles en los accesos.

- Crear zonas ajardinadas tanto dentro del aeródromo, como en los accesos del mismo.

-Cuidar al máximo el diseño de los edificios e instalaciones previstas.

-Controlar la posible tendencia del entorno del aeródromo a la localización urbanística.

Sobre población y empleo

La creación del aeródromo va a traer como consecuencia:

-un incremento de la mano de obra, de modo que sería conveniente que los empleados contratados, tanto para la construcción como la explotación, sean habitantes de la zona afectada.

-una recualificación de la mano de obra, estableciendo programas de formación y especialización (en posible colaboración del INEM)

Sobre clasificación urbanistica del suelo

El entorno del aeródromo debería quedar calificado urbanísticamente como no urbanizable común.

\section{PROGRAMA DE VIGILANCIA AMBIENTAL}

Tal y como se establece en el Artículo 11 del Real Decreto $1131 / 1988$, de 30 de septiembre, por el que se aprueba el Reglamento para la ejecución del Real Decreto 1302/1986, 
de 28 de junio, de Evaluación de Impacto Ambiental, el Plan de Vigilancia Ambiental tiene por objeto establecer un sistema para comprobar la veracidad de los impactos previstos, la posible aparición de otros y garantizar el cumplimiento de las indicaciones y medidas, protectoras, correctoras y compensatorias, contenidas en la declaración de impacto ambiental.

\section{Procesos constructivos}

El titular comprobará continuamente que la producción de polvo y ruido por la maquinaria de movimiento de tierras, no resulta excesiva, dada la presencia de una urbanización próxima.

Al inicio de las obras de explanación se comprobará que efectivamente se retiran las tierras vegetales y se almacenan en montones de altura inferior a 1,4 metros para su posterior utilización en la revegetación de la zona.
Los edificios deberán seguir una tipología edificatoria, materiales y colores, que no desentonen con el carácter del entorno.

\section{Fase de explotación}

Para verificar las afecciones debidas al ruido se realizarán medidas del ruido en los períodos y momentos de máxima intensidad de tráfico y en los períodos más críticos. Estos controles se harán preferentemente en la zona de la urbanización.

Se llevará un registro de los accidentes sobrevenidos a las aves como consecuencia del tráfico aéreo.

Periódicamente se comprobará que no se producen vertidos accidentales de aceites o combustibles, así como de otros elementos de desecho.

\section{Publicaciones del Instituto Eduardo Torroja-CSIC}

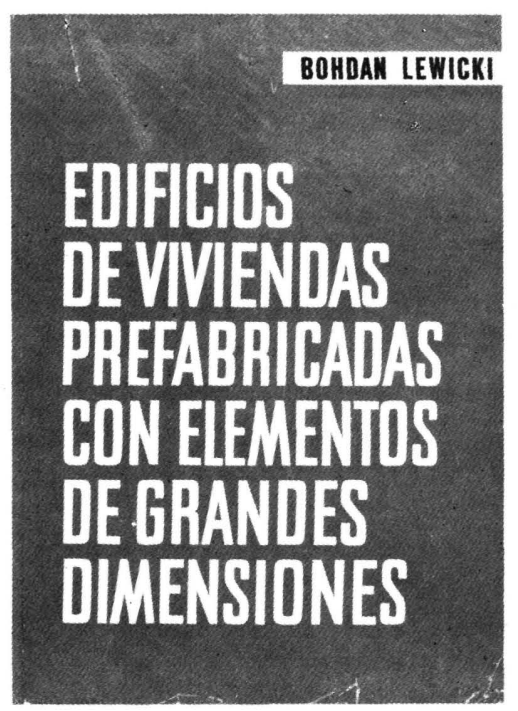

Bohdan Lewicki

Este libro trata de los problemas relativos a la construcción de los edificios de viviendas o publicos realizados con elementos prefabricados de grandes dimensiones. Se han estudiado los problemas de arriostramiento asi como los que plantea la resistencia de los elementos y de la estructura; se han examinado las cuestiones de orden higrotèrmico, acústico y de resistencia al fuego; también se ha profundizado en el estudio de la estanquidad de los muros exteriores y de las juntas.

La obra incluye numerosas ilustraciones que dan detalles de diversas soluciones, asi como ejemplos de cálculo, tablas de valores numéricos, diagramas y ábacos.

Un volumen encuadernado en tela, de $24 \times 17 \mathrm{~cm}$, compuesto de 616 págs.
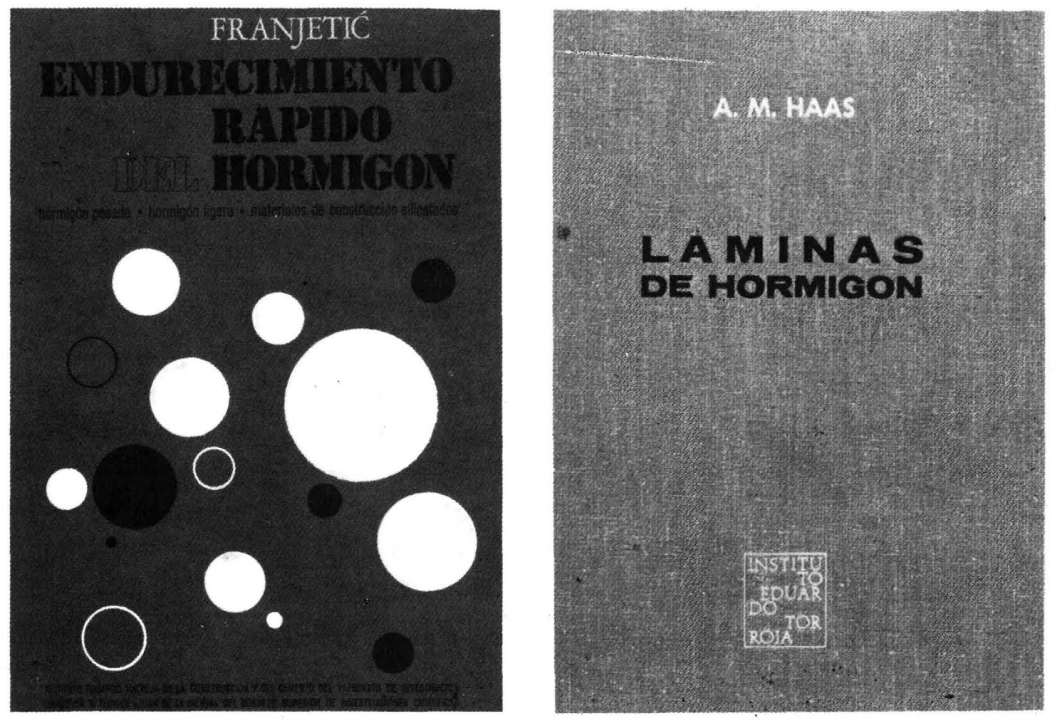

Zorislav Franjetić

En la obra de Franjetic se expone de una forma minuciosa, ordenada y sistemática, todo un cuerpo de doctrina que reúne el conocimiento actual sobre el endurecimiento rápido del hormigón. Parte el autor de los principios básicos y llega a las últimas consecuencias y realidades técnicas y econo micas.

Es una obra de consulta, tanto para el investigador sobre la materia, como para el proyectista y el realizador y montador de plantas e instalaciones y equipos de curado y endurecimiento rápido.

Un volumen encuadernado en cartóné, de $17 \times 24,5 \mathrm{~cm}$, compuesto de 385 págs. 110 figuras y 10 tablas.

\section{A. M. Haas}

Al escribir este libro el autor intento poner a disposición de los estudiantes y de los ingenieros unos conocimientos prácticos, adecuados para servir de guia en el diseño y construcción de láminas delgadas de hormigón.

El autor está convencido de que el éxito en el diseño de una lámina exige, por parte del proyectista, un examen de las tres fases por las que pasa la materialización de la lámina: el diseño, el análisis estructural y la construcción de la estructura.

Un volumen encuadernado en tela, de $17 \times 24,5 \mathrm{~cm}$, compuesto de 420 págs., 141 figuras, 22 fotografias y 6 tablas. 